San Jose State University

SJSU ScholarWorks

Master's Theses

Master's Theses and Graduate Research

1994

\title{
Effects of aerobic exercise on response time components of 34 to 46 year old women
}

Lynn E. Johnson

San Jose State University

Follow this and additional works at: https://scholarworks.sjsu.edu/etd_theses

\section{Recommended Citation}

Johnson, Lynn E., "Effects of aerobic exercise on response time components of 34 to 46 year old women" (1994). Master's Theses. 845.

DOI: https://doi.org/10.31979/etd.3jxw-x7pb

https://scholarworks.sjsu.edu/etd_theses/845

This Thesis is brought to you for free and open access by the Master's Theses and Graduate Research at SJSU ScholarWorks. It has been accepted for inclusion in Master's Theses by an authorized administrator of SJSU ScholarWorks. For more information, please contact scholarworks@sjsu.edu. 


\section{INFORMATION TO USERS}

This manuscript has been reproduced from the microfilm master. UMI films the text directly from the original or copy submitted. Thus; some thesis and dissertation copies are in typewriter face, while others may be from any type of computer printer.

The quality of this reproduction is dependent upon the quality of the copy submitted. Broken or indistinct print, colored or poor quality illustrations and photographs, print bleedthrough, substandard margins, and improper alignment can adversely affect reproduction.

In the unlikely event that the author did not send UMI a complete manuscript and there are missing pages, these will be noted. Also, if unauthorized copyright material had to be removed, a note will indicate the deletion.

Oversize materials (e.g., maps, drawings, charts) are reproduced by sectioning the original, beginning at the upper left-hand corner and continuing from left to right in equal sections with small overlaps. Each original is also photographed in one exposure and is included in reduced form at the back of the book.

Photographs included in the original manuscript have been reproduced xerographically in this copy. Higher quality $6 "$ " 9 9" black and white photographic prints are available for any photographs or illustrations appearing in this copy for an additional charge. Contact UMI directiy to order.

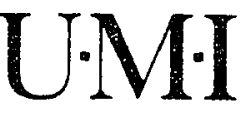

University Microfilms Internationa!

A Bell \& Howell Information Company

300 North Zeeb Road. Ann Arbor. MI 48106-1346 USA

313/761-4700 800/521-0600 

Order Number 1859028

Effects of aerobic exercise on response time components of 34 to 46 year old women

Johnson, Lynne, M.A.

San Jose State University, 1994

Copyright (C)1998 by Jchnson, Lysne. All rights reserved.

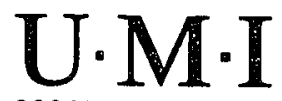

300 N. Zeeb Rd.

Ann Arbor, MI 48106 

EFFECTS OF AEROBIC EXERCISE ON RESPONSE TIME COMPONENTS

OF 34 TO 46 YEAR OLD WOMEN

\author{
A Thesis \\ Presented to \\ The Department of Human Performance \\ San Jose State University \\ In Partial Fulfillment \\ Of the Requirements for the Degree \\ Master of Arts
}

By

Lynne Johnson

August, 1994 
(C) 1993

Lynne Johnson

ALL RIGHTS RESERVED 
APPROVED FOR THE DEPARTMENT OF HUMAN PERFORMANCE
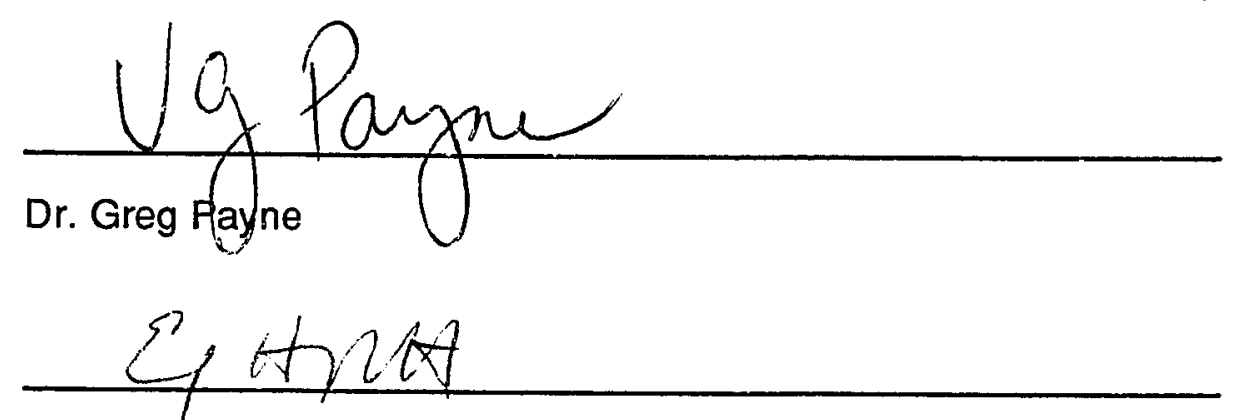

Dr. Emily Wughalter

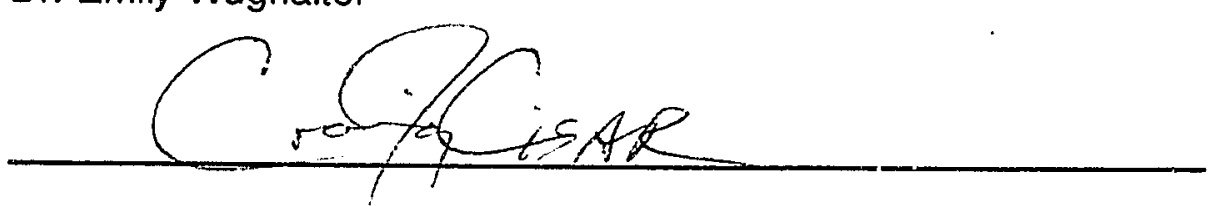

Dr. Craig Cisar

APPROVED BY THE UNIVERSITY

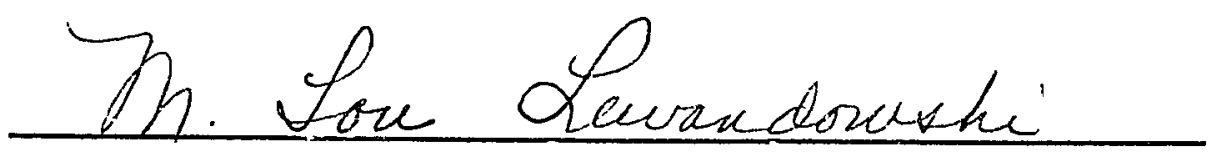




\section{ABSTRACT \\ EFFECTS OF AEROBIC EXERCISE ON RESPONSE TIME COMPONENTS OF 34 TO 46 YEAR OLD WOMEN \\ by Lynne Johnson}

The effect of a 10 week continuous walking and/or jogging program on simple and discrimination reaction and movement time in 15 women, ages 34 to 46 years, was examined. Subjects volunteered to participate in either an exercise or control group.

Analysis of adjusted posttest means revealed no significant differences between the two groups for simple and discrimination reaction time (SRT, DRT) or simple movement time (SMT). Statistical differences were found between the two groups for estimated $\mathrm{VO}_{2}$ max and for discrimination movement time (DMT). Significantly faster DMT in the exercise group following training was coupled with slower DRT, indicating a task time trade-ofí between reaction and movement time.

Significant relationships were found between pretest $\mathrm{VO}_{2}$ max and DRT and between posttest $\mathrm{VO}_{2} \max$ and DMT. These results provide additional support for a trade-off and suggest that fitness is important to both central and peripheral components of response time in complex tasks. 


\section{Acknowledgements}

I would like to acknowledge and extend my gratitude to several people who have contributed to this thesis and to my educational experience here at San Jose State.

First, I would like to thank my Committee chairperson, Dr. Greg Payne, for his support and encouragement in undertaking this research. I also appreciate the availability and willingness of my Committee members, Dr. Emily Wughalter and Dr. Craig Cisar, to assist me throughout this project. I would also like to thank the faculty and staff in the Department of Human Performance who have contributed in many direct and indirect ways to the successful completion of this thesis and my degree.

To my parents, Kaye and John, my brother Randy, and my sister Lori: thank you for always encouraging me to pursue my dreams and for being there to share in the celebration when they are realized.

Finally, I would like to thank my husband Ed, to whom this thesis is dedicated. Your love, support, encouragement, and determination to see me through to the end has been invaluable. 


\section{Table of Contents}

\section{Page}

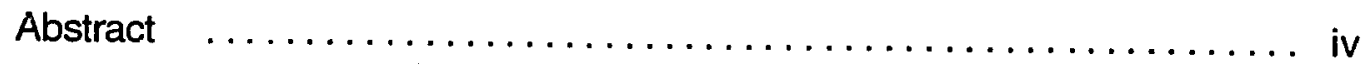

Acknowledgements $\ldots \ldots \ldots \ldots \ldots \ldots \ldots \ldots \ldots \ldots \ldots \ldots, \ldots$

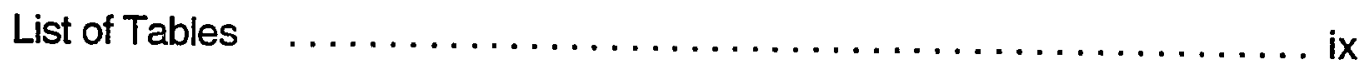

Chapter

1. Introduction $\ldots \ldots \ldots \ldots \ldots \ldots \ldots \ldots \ldots \ldots \ldots \ldots \ldots \ldots \ldots \ldots$

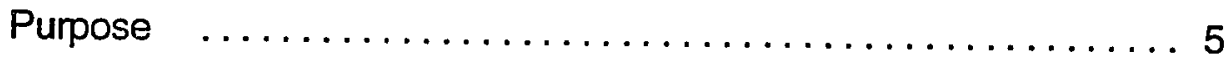

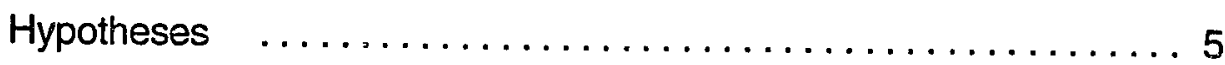

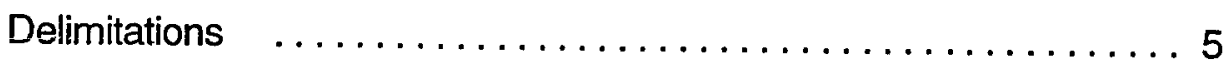

Limitations $\quad \ldots \ldots \ldots \ldots \ldots \ldots \ldots \ldots \ldots \ldots \ldots \ldots \ldots$

Definitions and Operational Definitions $\ldots \ldots \ldots \ldots \ldots \ldots 6$

Summary $\ldots \ldots \ldots \ldots \ldots \ldots \ldots \ldots \ldots \ldots \ldots \ldots, 8$

2. Review of Literature $\ldots \ldots \ldots \ldots \ldots \ldots \ldots \ldots \ldots \ldots \ldots$

Introduction $\ldots \ldots \ldots \ldots \ldots \ldots \ldots \ldots \ldots \ldots \ldots, 9$

Effect of Exercise on Response Time

Physiological Mechanisms $\ldots \ldots \ldots \ldots \ldots \ldots \ldots$

Motor Unit Characteristics $\ldots \ldots \ldots \ldots \ldots \ldots . \ldots . \ldots 10$

Trophic Effect of Physical Activity $\ldots \ldots \ldots \ldots \ldots \ldots$

Structural Changes in the Nerve Cell $\ldots \ldots \ldots \ldots \ldots 11$

Neuroendocrine Adaptations to Exercise $\ldots \ldots \ldots \ldots 11$

Exercise Effects on Cerebral Blood Flow $\ldots \ldots \ldots \ldots 11$

Relationship Between $\mathrm{VO}_{2}$ max and Components of

Response Time $\quad \ldots \ldots \ldots \ldots \ldots \ldots \ldots \ldots \ldots \ldots \ldots$ 
Effect of Training on Components of Response Time Training Studies $\ldots \ldots \ldots \ldots \ldots \ldots \ldots \ldots \ldots \ldots \ldots \ldots \ldots$

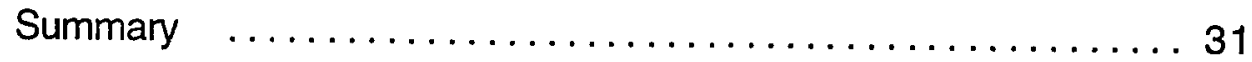

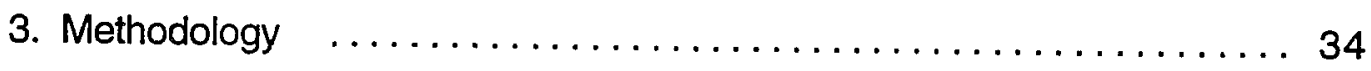

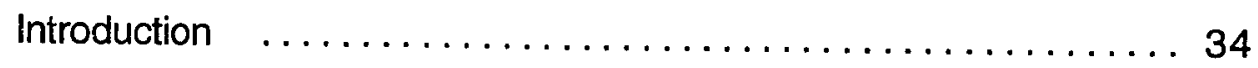

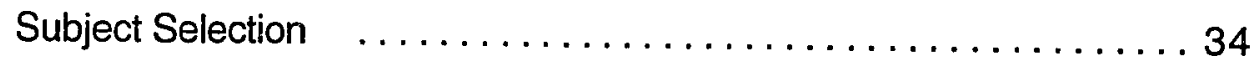

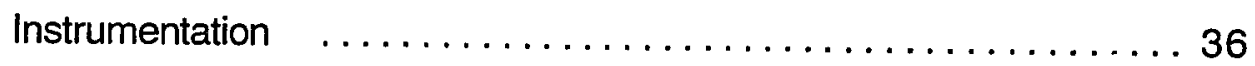

Reaction Time and Movement Time $\ldots \ldots \ldots \ldots \ldots 36$

Pre- and Posttesting Measurement Procedures $\ldots \ldots \ldots \ldots 36$

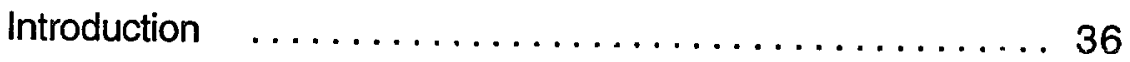

Body Composition and Size $\ldots \ldots \ldots \ldots \ldots \ldots \ldots . \ldots 37$

Reaction and Movement Time $\ldots \ldots \ldots \ldots \ldots \ldots . \ldots 37$

VO2max Estimation $\ldots \ldots \ldots \ldots \ldots \ldots . \ldots . \ldots . \ldots . \ldots 39$

Training Procedures $\ldots \ldots \ldots \ldots \ldots \ldots \ldots \ldots \ldots . \ldots . \ldots . \ldots$

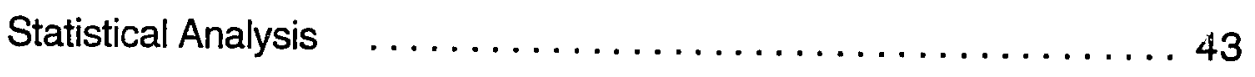

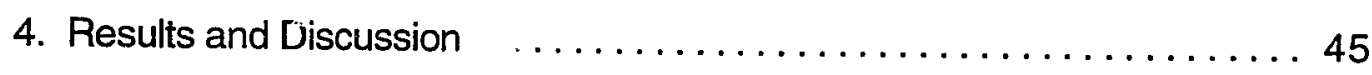

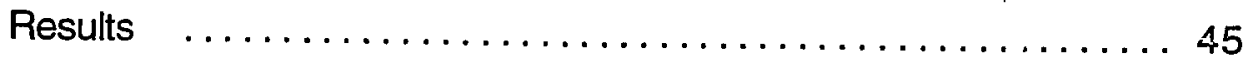

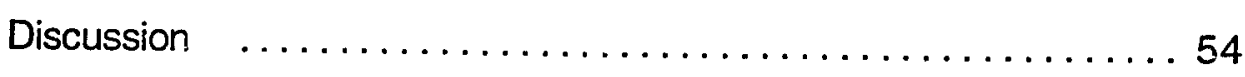

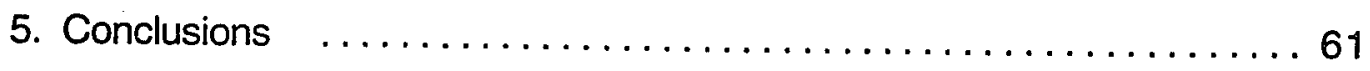

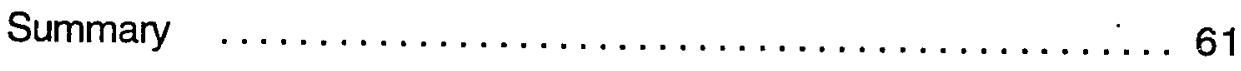

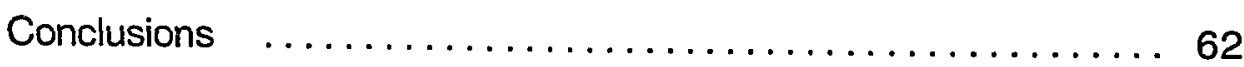

Recommendations $\ldots \ldots \ldots \ldots \ldots \ldots \ldots \ldots \ldots \ldots .63$

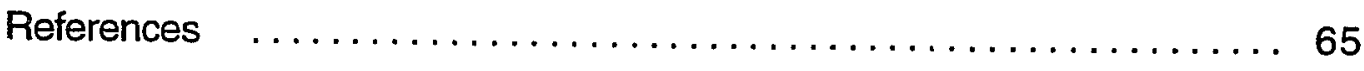




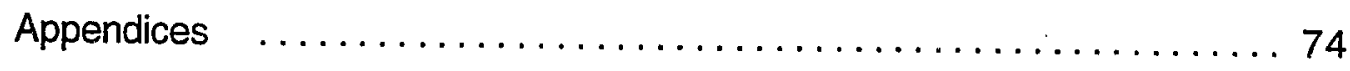

A. Health History Questionnaire $\ldots \ldots \ldots \ldots \ldots \ldots . \ldots . \ldots 4$

B. Informed Consent $\ldots \ldots \ldots \ldots \ldots \ldots \ldots \ldots \ldots \ldots, 78$

C. Response Time Data Sheet $\ldots \ldots \ldots \ldots \ldots \ldots \ldots . \ldots 1$

D. Summary Data Sheet $\ldots \ldots \ldots \ldots \ldots \ldots \ldots . \ldots . \ldots . \ldots . \ldots 4$

E. Rating of Perceived Exertion or "RPE" Chart $\ldots \ldots \ldots \ldots .85$

F. Standardized Instructions $\ldots \ldots \ldots \ldots \ldots \ldots \ldots \ldots$ 


\section{List of Tables}

Tables

1. Descriptive Characteristics of Exercise and Control Group $\ldots \ldots 46$

2. Table of Means and Summary Analysis of Covariance for Estimated $\mathrm{VO}_{2} \max \quad \ldots \ldots \ldots \ldots \ldots \ldots \ldots \ldots \ldots \ldots, \ldots \ldots \ldots$

3. Table of Means and Summary Analysis of Covariance

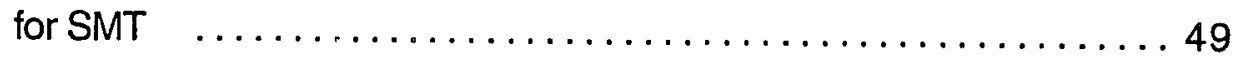

4. Table of Means and Summary Analysis of Covariance

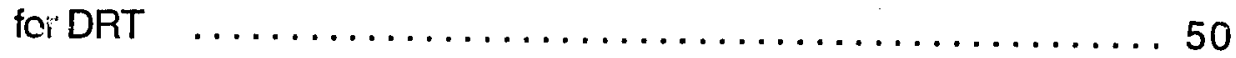

5. Table of Means and Summary Analysis of Covariance

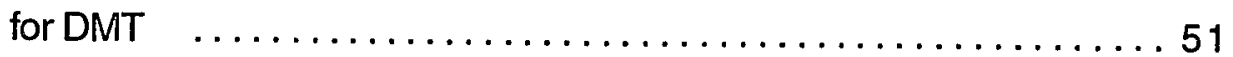

6. Table of Means and Mann-Whitney $\underline{\cup}$ Test for SRT $\ldots \ldots \ldots \ldots 52$

7. Correlations Between Estimated $\mathrm{VO}_{2}$ max and Timing Variables $\ldots 53$ 


\section{Chapter 1}

\section{Introduction}

The speed with which one reacts to a stimulus is critical in physical activities such as baseball, tennis, sprinting, and hockey. However, the ability to respond quickly has relevance beyond sports. Reacting fast enough to prevent a fall or avoid an accident while driving are examples of the importance of quick responses in daily living. A decline in our ability to respond quickly could have health and safety implications, and yet this is precisely what appears to happen as we age. Birren, Woods, and Williams, in a 1979 review, stated that "perhaps the most ubiquitous and significant change observed in the older organism is slowness of behavior" (p. 10).

Both components of response time, reaction time and movement time, have been found to slow with age, with the increase beginning in early adulthood (Hodgkins, 1963; Pierson \& Montoye, 1958). Although both components have been the subject of aging research, much of the focus has been on reaction time. In fact, the decline of simple reaction time with age has been described as "one of the most replicated findings of behavioral change with age" (Birren et al., 1979, p. 13). The decline in reaction time is even more apparent as the complexity of the task increases (Cerella, Poon, \& Williams, 1980). Reaction time is of interest because of its importance to motor functions and because it is seen as an indicator of overall central nervous system integrity (Birren et al., 1979). 
Using electroniiyography (EMG), reaction time can be fractionated into premotor and motor time. Motor time is associated with the biochemical and biomechanical properties of the muscles while premotor time is believed to represent central processes such as perception and decision making (Schmidt, 1988). A decline in central processing as measured by premotor time has been identified as the primary contributor to slowing of reaction time (Weiss, 1965; Botwinick \& Thompson, 1966). The mechanisms responsible for slowing of behavior with age are not yet understood; however, researchers have suggested that the decline in CNS processing may be due to reduced cerebral blood flow and decreased oxygen availability to the brain resulting in declines in cerebral metabolism (Spirduso, 1980).

Although declines in reaction time and movement time with age have been well documented, the rate and extent of the decline varies greatly between individuals (Spirduso, 1980). There is some evidence that older adults who maintain an active lifestyle retain reaction and movement times similar to young inactive adults and significantly faster thran the sedentary elderly (Spirduso, 1975). The mechanisms by which exercise affects response time are unknown. However the possibility exists that exercise, particularly aerobic exercise, may help to maintain cerebral blood flow and the oxidative capacity of the brain, and produce a stimulating effect on the motor neurons innervating the muscle fibers (Spirduso, 1980).

In addition to Spirduso's 1975 investigation, considerable crosssectional literature suggests a strong relationship between physical activity and psychomotor speed. Such studies typically compare a group of athletic or active subjects and a group of nonathletes or inactive subjects on a 
reaction/movement time test. Although fitness level was not always monitored, the active group or athletes, by virtue of their activity, are assumed to be more physically fit than their sedentary counterparts. Research of this nature has overwhelmingly found the athletic or active groups to have faster reaction and movement times across genders, age groups, and different types and degrees of physical activity (Baylor \& Spirduso, 1988; Clarkson, 1978; Knapp, 1961; Olsen, 1956; Rikli \& Busch, 1986; Sherwood \& Selder, 1979; Spirduso \& Clifford, 1978; Youngen, 1959). However, with a cross-sectional design the question exists: are the athletes or active subjects faster because of training or are they predisposed to activity because of inherently faster response times? Another question arising from these descriptive studies is whether regular exercise contributes to faster reactions and movements, or whether it prevents or slows the decline in these variables typically seen with age.

To address these questions, and to better understand the relationship between exercise and response time components, research employing an exercise intervention is required. Although findings from descriptive studies are convincing in suggesting such a relationship, the results of training studies have been contradictory. Using male college-aged subjects, Hascelik, Basgoze, Turker, Narman, and Ozker (1989) reported significant increases in reaction time rneasures following an eight week exercise program. Tweit, Gollnick, and Hearn (1963) yielded similar results with six weeks of training. On the other hand, Powell (1983) found no change in reaction time measures in young men completing seven weeks of exercise. Studies using an exercise intervention with elderly subjects were more numerous, but equally equivocal. Roberts (1990) and Whitehurst (1991), for example, reported no change in components 
of response time in elderly subjects following exercise training while Dzewaltowski (1985) and Vanfraechem and Vanfraechem (1977) reported significantly improved reaction times after exercise programs lasting from six to eight weeks.

In citing the need for additional exercise intervention studies, several reviews have highlighted methodological problems in the training literature that make interpretation of findings difficuit. These problems include inadequate numbers of trials to offset the effects of learning, no control group, exercise interventions of low intensity and/or short duration, lack of control of health factors such as smoking, and no assessment of the effectiveness of the intervention on aerobic fitness (Baylor, 1989; Spirduso, 1980, 1982; Toole \& Abourezk, 1989).

In addition to these problems, training studies have primarily utilized college students or the elderly leaving a paucity of research conducted on subjects between 25 and 50 years of age. Understanding whether exercise impacts psychomotor speed and assessing how age, psychomotor speed, and physical activity interact is necessary to determine the efficacy of exercise intervention in preventing behavioral slowing with age. Thus, the need exists for training studies across all ages. Determining whether physical activity helps maintain or improve psychomotor speed would be valuable for sports participation, an individual's health and safety, and work productivity. If a decline in our reaction time, movement time, and central nervous system function could be prevented via physical activity, our aging society could benefit through greater independence and a longer, more productive life. 


\section{Purpose}

The purpose of this study was to examine the effect of aerobic exercise on simple and discrimination reaction time and movement time of 34 to 46 year old women.

\section{Hypotheses}

1. There will be no significant difference between the adjusted posttest means of the exercise and control groups for maximal oxygen consumption ( $\mathrm{VO}_{2} \mathrm{max}$ ), simple reaction time, movement time following simple reaction time, discrimination reaction time, or movement time following discrimination reaction time.

2. There will be no significant correlations among $\mathrm{VO}_{2} \max$ and simple or discrimination reaction time and movement time.

\section{Delimitations}

The following delimitations existed in the conduct of this research:

1. Subjects were female volunteers.

2. Subjects were nonsmokers.

3. Subjects were normally active for the six months preceding the commencement of the research.

4. Subjects drove automobiles.

5. Subjects were apparently healthy individuals as defined by the American College of Sports Medicine (1991).

6. Subjects had a body mass index (BMI) of less than $27.3 \mathrm{~kg} / \mathrm{m}^{2}$. 
Limitations

The following limitations existed in this study:

1. Subjects volunteered for either the control or exercise group. Volunteers for either group may not represent the general public.

2. Outside activities of both the control and exercise group during the period of the study could not be controlled.

3. The motivation of the subjects could not be controlled.

4. The changes that occurred in normally active, apparently healthy females may not be indicative of potential changes in males, females of other ages, or females with pathological conditions.

5. The ability to generalize results is limited by the small number of volunteers.

6. The effect of the exercise on the subjects' fitness was based on estimated $\mathrm{VO}_{2}$ max as determined by a one mile walk test rather than a direct assessment of $\mathrm{VO}_{2} \max$.

\section{Definitions and Operational Definitions}

Response time. The sum of reaction time and movement time (Schmidt, 1988, p. 65). In this study response time was defined as the time elapsing between the presentation of a red light and the depression of the left foot pedal (completion of the required movement) by the subject.

Reaction time. "A measure of the time from the arrival of a suddenly presented and unanticipated signal to the beginning of the response to it" (Schmidt, 1988, p. 64). Reaction time represented the time elapsing between the presentation 
of a red light and the removal of the right foot from the right foot pedal by the subject.

Simple reaction time. A reaction time measurement which does not require subjects to make a choice between responses. For the measurement of simple reaction time in this study, subjects were presented only with a red light and were required to use the same response.

Discrimination reaction time. A reaction time measurement which requires subjects to choose between responding or not responding. For the measurement of discrimination reaction time in this study, subjects were randomly presented with either a red or green stimulus. A response was required for the red light only.

Movement time. "The interval from the initiation of the response (the end of reaction time) to the completion of the movement" (Schmidt, 1988, p. 65). Movement time was calculated as response time minus reaction time. Aerobic exercise. Exercise that uses at least $50 \%$ or more of muscle mass in a rhythmic and continuous manner (Schroeder, 1990). In this research, continuous walking or jogging for 30 minutes or more was considered aerobic exercise.

VO2max. "The maximal rate at which oxygen can be consumed per minute; the power or capacity of the aerobic or oxygen system" (Fox, Bowers, \& Foss. 1988, p. 698). In this research $\mathrm{VO}_{2}$ max was estimated using a one mile walk test.

Normally active subjects. Operationally defired as an individual who was not participating in aerobic exercise for more than an average of one hour a week at a moderate intensity (rating of perceived exertion of 12 on the Borg RPE scale) or greater for the six months preceding the pretest. 
Middle-aged. Operationally defined as an individual between 25 and 50 years of age.

\section{Summary}

Both reaction time and movement time have been found to slow with age, with the decline beginning in early adulthood (Hodgkins, 1963; Pierson \& Montoye, 1958). This apparently inevitable decline has obvious implications for sports activities, but the ability to detect and respond quickly and effectiveiy is necessary in everyday activities such as driving. Moreover, reaction time is commonly used as an indicator of central nervous system integrity (Birren et al., 1979). Aerobic exercise has been suggested as a means of maintaining or slowing the decline in performance of psychomotor tasks by helping to maintain cerebral circulation and oxidative capacity of the brain and by producing a stimulating effect on motor neurons (Spirduso, 1980). Findings of crosssectional studies are robust in suggesting an exercise/response time relationship; however, training studies have produced mixed results. Problems in the existing studies have been identified and make interpretation of findings difficult (Baylor, 1989; Spirduso, 1980). Whether response time can be improved by participating in an exercise program has not yet been determined, therefore the purpose of this research was to examine the effect of aerobic exercise on simple and discrimination reaction time and movement time of middle-aged women. 


\section{Chapter 2}

\section{Review of Literature}

Introduction

This review of literature consists of three sections. The physiological miechanisms by which exercise may postpone the typical ago-related decline in psychomotor speed are reviewed first. The second section covers studies which have examined the relationship between $\mathrm{VO}_{2}$ max and reaction and/or movement time. In the third section, training studies examining the effect of exercise on response time components are reviewed. Finally, a summary of this chapter is presented.

\section{Effect of Exercise on Response Time: Physiological Mechanisms}

In 1980 and 1982 reviews, Spirduso discussed several mechanisms by which exercise might postpone declines observed in psychomotor speed with age. The information provided in these reviews is summarized and discussed here to provide background information and a theoretical basis for examining the effect of exercise on response time components. More recent investigations are integrated into this discussion where appropriate.

Spirduso (1982) identified cellular and system levels where exercise may influence response time. Cellular mechanisms included changes in motor unit characteristics, the trophic effect of physical activity, and structural changes in the nerve cell. System mechanisms addressed were neuroendocrine adaptations to exercise and exercise effects on cerebral blood flow. 
Motor Unit Characteristics. A motor unit is defined as a motor neuron and the muscle fiber(s) it innervates. A decline in the number of motor neurons with age has been demonstrated (Brown, 1972). This decline appears to preferentially affect motor neurons innervating type II (fast glycolytic, fast oxidative glycolytic) muscle fibers (Larsson, 1982). A reduction in the size and number of muscle fibers also occurs with age manifested, again, predominantly in type II muscle fibers (Aniarisson, Grimby, Hedberg, \& Krotkiewski, 1981; Lexell, Henriksson-Larsen, Winblad, \& Sjostrom, 1983; Tomonaga, 1977). A decline in muscular activity (or disuse) produces similar results: a loss or atrophy of muscle fibers, especially fast twitch fibers (Faulkner, Maxwell, \& Lieberman, 1972). Since type II muscle fibers are important in rapidly generating muscle tension, their reduction with age or inactivity could have an impact on psychomotor speed. Habitual physical activity may postpone or reduce the changes seen in motor units with age and disuse.

Trophic Effect of Physical Activity. The decline in physical activity that typically accompanies aging results in a decrease in the number and frequency of neuronal firings. Such disuse would negatively impact the neuromuscular system since muscular activity has been shown to have a stimulating effect on the neurons innervating the activated muscle fibers, and their immediate connections (Eccles, 1973). What impact regular muscular contraction has on higher nervous centers is unknown, however frequent firing of action potentials may have a trophic effect on the whole neural pathway involved in the movement. More specifically, chronic exercise may have a beneficial effect on the synthesis and maintenance of optimal levals of brain neurotransmitters, particularly dopamine, norepinephrine and serotonin. 
Structural Changes in the Nerve Cell. With age, a decline in the number of dendrites in the brain occurs (Feldman \& Dowd, 1975; Smith \& Sethi, 1975) which may lead to functional declines. Evidence that physical activity may postpone this change exists in studies of animals reared in conditions allowing different degrees of exercise. Monkeys provided an opportunity for play were found to have more Purkinje cell dendritic branching than movement deprived monkeys (Floeter \& Greenough, 1979). Additionally, mice exposed to daily exercise had heavier brains, greater Purkinje cell spine density and larger and more dendritic spines than inactive mice (Pysh \& Weiss, 1979).

Neuroendocrine Adaptations to Exercise. Alterations in several hormones have been reported with age. Physical conditioning has also been shown to affect hormone production and release at rest and/or during exercise. Researchers have proposed that hormones acting on brain cells may accelerate the aging process (Landfield, Lindsey, \& Lynch, 1978). Spirduso (1982) suggests that habitual physical activity may "maintain hormonal regulatory systems, consequently controlling key enzymatic functions that influence nervous system integrity" (p. 139).

Exercise Effects on Cerebral Blood Flow. In 1963, McFarland proposed a hypoxia model of aging based on observations that elderly subjects demonstrated impairments similar to individuals in hypoxic (oxygen-deprived) conditions. He proposed that with age there is a decline in the availability and/or use of oxygen in the CNS possibly due to a reduction in the amount of oxygen in the blood, a reduction in the amount of blood delivered to the brain (cerebral blood flow), or a decreased ability of the cell to take in or use oxygen. 
Indirect support for this theory exists in studies where subjects were given supplemental oxygen treatments. Elderly men treated with exposures of up to $100 \%$ oxygen, twice a day for 15 days demonstrated improvement on psychological tests (Jacobs, Winter, Alvis, \& Small, 1969). More recent studies which have tested older men and women of different fitness levels have not found that hyperoxia resulted in improved psychomotor speed (Abourezk, 1990; Fletcher, 1985). However, these studies measured reaction times during acute exposure to supplemental oxygen rather than following a period of repeated exposures.

Additional support also lies in examination of psychomotor speed in subjects with cardiovascular diseases, such as artereosclerosis, which reduce cerebial blood flow. For example, subjects with cardiac insufficiency demonstrated slower reaction times, as did subjects categorized as predisposed to cardiovascular disease (Abraharns \& Birren, 1973; Hicks \& Birren, 1970). Spirduso (1980) proposes that "cerebral circulatory insufficiency, hypoxia, or hypertension lead to secondary tissue damage, a reduction in metabolic rate, neuronal degeneration and finally to a decrease in cognitive and psychomotor function" (p. 857).

Declines in cerebral blood flow of up to $50 \%$ in subjects over 50 years of age have been documented in research (Kety, 1956). In a study examining 44 men and women, ages 19 to 79 , declines in regional cerebral blood flow were found to occur progressively throughout the lifespan (Melamed, Lavy, Bentin, Cooper, \& Rinot, 1980). Ingjer (1978) reported a linear relationship between blood flow and oxygen uptake in body tissues and Spirduso suggests a similar relationship may exist in the brain as well (1980). Regular physical activity may 
improve or maintain blood flow to areas of the brain associated with movement, and thereby ensure adequate oxygen for brain metabolism. Although research in this area is limited and contradictory, significant increases in blood flow to brain regions associated with movement were found in dogs while running on a treadmill (Gross, Marcus, \& Heistad, 1980).

\section{Relationship Between VO2max and Components of Response Time}

Based on laboratory observations, McFarland (1963) proposed a relationship between aging, and diminished oxygen transport and utilization in the central nervous system. Regular aerobic exercise has been proposed as a means of maintaining cerebral blood flow to areas involved in movement control and in ensuring an adequate supply of oxygen to the brain tissues by maintaining oxygen consumption (Spirduso, 1980). Maximal oxygen consumption ( $\mathrm{VO}_{2}$ max) is reflective of the body's efficiency in extracting and transporting oxygen during strenuous work, with higher $\mathrm{VO}_{2}$ max values reflecting greater efficiency. Reaction time measures are believed to represent efficient CNS functioning (Birren et al., 1979). VO2max is improved by regular aerobic exercise and thus is higher in active individuals. Active individuals also demonstrate faster reaction and movement times (Spirduso, 1975). Thus, one method of determining the role of physical activity in maintaining or improving psychomotor speed and brain function would be to examine the relationship between $\mathrm{VO}_{2} \mathrm{max}$ and response time components.

Chodzko-Zajko and Ringel (1987) examined relationships between sensory and motor performance tests (including reaction time) and two different measures of physiological fitness: an Index of Physiological Status (IPS) and 
estimated $\mathrm{VO}_{2}$ max. $\mathrm{VO}_{2}$ max was predicted on 47 men, ages 40 to 84 , using $\mathrm{VO}_{2}$ measured while the subject was walking on a treadmill at $80 \%$ of his predicted maximum heart rate. The IPS was generated using measures of lean body weight, systolic blood pressure, diastolic blood pressure, forced vital capacity, forced expiratory volume, serum triglyceride and serum cholesterol/high density lipoprotein. Reaction time measures required subjects to discriminate between two different colored stimuli presented on a screen.

Forty triais requiring discrimination between red and yellow stimuli were considered easy (RT easy) while 40 trials requiring discrimination between blue and green stimuli were considered difficult (RTdiff). Both reaction time measures, RT easy and RT diff, were significantly correlated with age $(\tilde{I}=.53$ and .61 , respectively) and significantly correlated with the IPS $(r=-.36$ and -.40 , respectively). They were not significantly correlated with predicted $\mathrm{VO}_{2} \max (r=$ -.20 and -.13 , respectively).

In contrast, Dzewaltowski (1985) found significant correlations between VO2max and reaction time measures, although his sample size was considerably smaller. VO2max was predicted via a submaximal treadmill test in young adults $(\underline{n}=5$, mean age $=28.80$ years) and older adults $\underline{n}=9$, mean age $=58.88$ years). Simple and choice fractionated reaction time measures of the lower leg were obtained from the subjects following one day of practice. Predicted $\mathrm{VO}_{2}$ max was significantly correlated with measures of simple reaction time $(r=-.60)$, choice reaction time $(r=-.66)$ and choice motor time $(r=$ -.68). Dzewaltowski then subjected the volunteers to an eight week aerobic exercise training period. Posttests revealed that $\mathrm{VO}_{2}$ max improved, however 
ro significant relationship existed between the percent change in $\mathrm{VO}_{2}$ max and changes in reaction time measures.

The results of a treadmill test were used to estimate $\mathrm{VO}_{2}$ max in both young ( $\underline{n}=28$; ages 20-35) and older ( $\underline{n}=9$; ages 60-75) male and female subjects in a study examining the relationship between physical fitness and driving ability (West Virginia University, 1988). Fractionated simple reaction time and movement time measures were obtained using a driving simulator: in response to a red light, subjects moved their foot as quickly as possible from an accelerator to a brake. $\mathrm{VO}_{2}$ max was not significantly related to simple reaction time, its fractionated components, or movement time for either the young or older drivers, although the correlation between movement time and $\mathrm{VO}_{2} \mathrm{max}$ approached significance $(r=-.64, \underline{p}<.07)$ for the older subjects.

The usefulness of submaximal predictions of $\mathrm{VO}_{2}$ max to examine the relationship of aerobic fitness to response time measures is questionable, however, in light of the findings of Era, Jokela, and Heikkinen (1986). Tests of psychomotor speed were administered to men of three age groups: 31 to 35 years, 51 to 55 years, and 71 to 75 years. A direct assessment of VOZmax was obtained using a cycle ergometer for 103 subjects while it was predicted indirectly for 155 subjects. For the men completing the direct test, an indirect measure was also calculated. Correlation coefficients were determined for each of the $\mathrm{VO}_{2}$ measures with visual and auditory simple and choice reaction and movement time. No significant correlations were found between indirectly assessed $\mathrm{VO}_{2} \max$ and measures of psychomotor speed for any of the age groups. However, significant correlations were calculated between visual choice reaction time (VCRT) and directly assessed $\mathrm{VO}_{2}$ max in the 31-35 age 
group $(r=-.373)$. Significant relationships were also found between VCRT, movement time following VCRT, auditory choice reaction time, and directly assessed $\mathrm{VO}_{2}$ max in the 71 to 75 age group $r=-.682,-.661$, and -.676 , respectively).

Forth and Salmoni (1987) also studied the relationship between $\mathrm{VO}_{2} \mathrm{max}$ directly assessed on a treadmill and simple and choice reaction time (SRT, CRT), using three groups of young male subjects, ages 10-11, 17-18, and 23-24 years ( $\underline{n}=20$ per group). For the oldest group, significant correlations were calculated between SRT and absolute $\mathrm{VO}_{2} \max$ (in L/min, $\underline{r}=-.64$ ), SRT and relative $\mathrm{VO}_{2} \max$ (in $\mathrm{ml} / \mathrm{kg} / \mathrm{min}, \underline{r}=-.60$ ), CRT and absolute VO $2 \max (\underline{r}=-.73$ ), and $C R T$ and relative VOrmax $(r=-.59)$. Except for a significant correlation $(r=$ -.53) between CRT and relative $\mathrm{VO}_{2}$ max in the 17-18 age group, no other significant correlations were found in the youngest groups.

Fletcher (1985) aiso reported no significant relationship between $\mathrm{VO}_{2} \mathrm{max}$ and response time measures. Seventeen men and 15 women, ages 54 to 67 , had their $\mathrm{VO}_{2}$ max directly assessed on a maximal treadmill test. Subjects were given 5 practice trials followed by 20 test trials on a choice reaction time task. Neither choice reaction time nor movement time correlated significantly with measures of $\mathrm{VO}_{2} \max (r=.21$ and .40 , respectively).

Pariton, Graves, Pollock, Hagberg, and Chen (1990) directly assessed $\mathrm{VO}_{2}$ max on a treadmill before and after a six month training program in men and women, ages 70 to 79 . VO2max incieased significantly from pre- to posttest in the aerobic exercise group ( $\underline{n}=17$ ), and was significantly greater than that of the strength training group $(\underline{n}=20)$ and control group $(\underline{n}=12)$ following the training period. No significant relationships were found between 
initial $\mathrm{VO}_{2}$ max and initial measures of simple fractionated response time. A significant, although low, correlation $(r=.30)$ was calculated between changes in $\mathrm{VO}_{2} \mathrm{max}$ and total reaction time changes. No significant relationships were noted between $\mathrm{VO}_{2}$ max changes and changes in the fractionated components of total reaction time (premotor time, contractile time) or movement time.

\section{Effect of Training on Components of Response Time: Training Studies}

Another way of exploring the potential relationship between fitness and segmented response time is by studying untrained or sedentary subjects to determine if any component of response time improves following a training period. One of the earliest studies examining the effect of training on response time combined both a cross-sectional and training design. In the first part of the two part research study, Beise and Peaseley (1932) found the reaction time of both arms and legs to be faster in a group of college age women skilled in tennis, golf or archery compared to a group of unskilled women. The second part of their study examined whether training in any of the sports would result in improved reactions. Female university students enrolled in golf $(\underline{n}=8)$, tennis $(\underline{n}=10)$, and archery $(\underline{n}=8)$ physical education classes, with no previous training in that sport, were selected as subjects. Eight students not participating in any sport were the control group. All participants were tested at the beginning and end of a seven week training period. The activity classes met twice a week for one hour and consisted of instructional and game playing components. Although the subjects were not restricted from outside participation, only three of the tennis subjects reported playing in addition to the class time. Reaction time was measured as part of a combined speed, agility, 
and total body reaction time test devised by the authors. The reaction time component was measured as the time from a flashing light stimulus to the removal of the leg from a pressure sensitive floor plate. The measure was called total body reaction time because when the light flashed the subject began moving her entire body through a prescribed path for the speed and agility portions of the test. Reaction time for the armis was measured by having the subject push down on the plate or lift the hand from the plate in response to a flashing light. Subjects were given one practice trial and the number of reaction times collected for each subject ranged from 2 to 4 for the legs and 5 to 14 for the arms. Changes in reaction time following training were not significant. The results of the second part of the study seem to suggest that the faster reaction times seen in the women athletes in the first part of the study may be due to inherent abilities rather than the result of participation in physical activity.

A more vigorous, six week training program was used by Tweit et al. (1963). Subjects for this study were male college freshmen $(\underline{N}=26)$ who had relatively low scores on Rogers Physical Fitness Index (PFI). Twenty practice trials were administered prior to data collection. Pre- and posttests consisted of 10 total body reaction time measures with each foot. To address the possible effects of learning the authors compared the mean difference of the first 20 trials to the mean difference of the last 10 trials; because the difference between the two was not significant, they concluded that practice effects were minimal. Fitness changes due to training were assessed using the PFI, the Sargent Jump, and the Illinois Agility Run. Subjects attended four 30-minute training sessions each week. Approximately half that time was spent doing exercises to 
develop large muscle groups and the remainder of the time involved activities such as relays, sprints, and weight training. Total body reaction time decreased significantly $(\underline{p}<.01)$ from a mean of .508 seconds before training to a mean of .468 seconds after training. All fitness measures also improved significantly following training but there were no significant correlations between total body reaction time and any of the fitness measures. However, when composites of the improvement scores were correlated with the improvement in reaction time a significant relationship $(\underline{r}=.49, \underline{p}<.02)$ was noted between reaction time improvement and the composite improvement scores of the Illinois Agility Run and the Sargent Jump.

Aerobic exercise was used as the mode of intervention in a group of male subjects aged 20 to 45 years of poor to average fitness (Powell, 1983). All 36 subjects participated in the training regimen for one hour a day, five days each week for seven weeks. The workout included one day of each of the following activities: continuous swimming, continuous jogging, circuit training, interval training, and obstacle course running. Reaction time testing involved depressing one microswitch in response to a red stimulus light (simple reaction time) or one of four microswitches in response to the appropriate light stimulus (choice reaction time). Twenty-five trials were administered for simple reaction time ( 5 blocks of 5 trials) and 50 trials for choice reaction time ( 5 blocks of 10 trials). Since no control group was used, learning effects were considered by comparing each block of trials; when significant differences were no longer found between blocks, the remainder of the trials were then averaged.

Cardiorespiratory fitness was assessed using a bicycle ergometer to measure VO2max; muscular strength and muscular endurance of the quadriceps were 
also measured. All fitness measures increased significantly following training; however, no change was found in the reaction time measurements.

As with the previous two studies, no control group existed for a study using 20 male college volleyball players as subjects (Hascelik et al., 1989). The participants trained five days per week for eight weeks. Each training session consisted of a 20 minute warm-up, circuit weight training exercises, and a 20 minute stretching period. Although weight training was the mode of exercise, subjects maintained a pulse rate of approximately 150 to 170 beats per minute while performing the circuit, a stimulus equivalent to $75-85 \%$ of age predicted maximum heart rate. Both visual and auditory reaction time were measured as the mean of 10 trials. Subjects were also pre- and posttested for VO2max (using a treadmill) and strength. Analysis of gain scores using multiple $\underline{t}$ tests found significant increases in strength and $\mathrm{VO}_{2} \max (\underline{p}<.01)$, visual reaction time $(\mathrm{p}<.01)$, and auditory reaction time $(\mathrm{p}<.05)$ following the training period.

Dzewaltowski (1985) examined the effect of aerobic exercise on the fractionated components of reaction time in both young and elderly subjects. Subjects were screened for a history of cardiovascular disease and excludeci if they had smoked in the previous year or had participated in a previous exercise program. Dependent measures included simple and choice total reaction time, premotor and motor time, state and trait anxiety, resting heart rate, and estimated $\mathrm{VO}_{2}$ max. Reaction time measures were obtained following one day of practice; 40 simple and 50 choice reaction time trials were obtained. For pretest analysis, young $(\underline{n}=5$; mean age $=29.80$ years $)$ and old $(\underline{n}=9$; mean age $=58.88$ years) male and female volunteers were separated into four groups 
based on results of a submaximal treadmill test: old, high fit $(\underline{n}=5)$; old, low fit $(\underline{n}=4)$; young, high fit $(\underline{n}=3)$; and young, low fit $(\underline{n}=2)$. A two by two (age by fitness level) ANOVA was used to analyze the dependent variables. For simple reaction time there was a trend toward a significant main effect for fitness, with the high fit subjects faster than the low fit across the age groups. Analysis of simple premotor time revealed a significant main effect for fitness level, again with the high fit group faster than the low fit group. Examination of choice reaction time revealed similar results, a significant main effect for fitness for both choice reaction time and choice premotor time. All subjects thien underwent eight weeks of aerobic exercise training. Subjects participated in an individualized walking or jogging program, at an intensity of $70 \%$ of their heart rate reserve. Following completion of the training program, two different analyses using two by two ANCOVAs, with pretest values as covariates, were performed. Subjects were grouped by age (old, young) and percentage improvement in estimated $\mathrm{VO}_{2}$ max (high, low) in one analysis and by age and level of posttest fitness (high, low) in the second. The only significant interaction noted for either analysis was an age by level of posttest fitness on simple motor time for the high fit old and low fit young groups; the low fit old and high fit young showed no improvement. Matched t tests were calculated by age group to determine whether any significant changes occurred following training. Results indicated that older adults improved simple premotor time significantly which contributed to significantly improved total simple reaction time. Significantly faster choice premotor time was also calculated for the older group but did not lead to an improved total choice reaction time. 
Vanfraechem and Vanfraechem (1977) examined the responses of previously active $(\underline{n}=10)$ and previousiy sedeniary $(\underline{n}=10)$ elderly women to participation in one hour of physical training, twice a week for two months. Simple reaction time was measured by depressing a switch in response to visual, auditory, and tactile stimuli. Prior to the start of the two months of trainirig, the active group was significantly faster than the sedentary group for visual, auditory, and tactile reaction time. After training, the previously sedentary group recorded significant improvements in all reaction time measures while no significant differences were noted for the previously active group following training; moreover, following training significant differences no longer existed between the two groups.

In a similar design with a much longer training period, elderly volurteers met one hour a week for six months to determine the effect of aerobic exercise on fitness and psychological measures (Stacey, Kozma, \& Stones, 1985). A total of 66 elderly subjects who were members of an older ( $>50$ years) adult fitness club participated in the research. Twenty-nine of the subjects (11 males, 18 females) were new members of the club; the remaining 37 participants ( 11 males, 26 females) had been active in the club for one or more years. The mean age of the subjects was 58 years for the new members and 62 years for returning members. All subjects participated in the exercise program. The weekly exercise program consisted of a half hour of flexibility, balance and some type of aerobic activity; the remaining time was spent on participantmonitored swimming. Reaction time was measured using a ruier-dropping task: one end of a 36 inch ruler was suspended between the subject's finger and thumb (ungrasped). Reaction time was determined by the distance the ruler 
dropped before the subject grasped it. Fitness measurements included the step test for aerobic power, length of time the subject stood on each foot for balance, and the sit and reach test for flexibility. Other dependent variables included digir symbol, state and trait anxiety, happiness, and amount of outside physical activity. A group by pretest/posttest ANOVA with repeated measures on the last factor was calculated for each of the nine dependent variables. Significant pretest/posttest main effects were found for two of the fitness measures (flexibility and balance), for reaction time, for outside activity level, and for digit symbol. A significant group main effect was found only for reaction time and significant interactions occurred only for happiness and trait anxiety. Thus the club's returning members scored better on reaction time initially than the new members, and remained faster at the end of six months, however both groups combined improved reaction time significantly, pre- to posttest $(p=04)$. The exercise program and increased activity level were apparently not sufficient to produce a training effect on aerobic power or, as suggested by the authors, the test used may not have been sensitive enough to detect changes. The results seem to suggest that response time can be improved significantly by a moderate intensity exercise program and in the absence of an increase in aerobic power.

Normand, Kerr, and Metivier (1987) examined the effects of 10 weeks of exercise on choice reaction time and movement time of 24 seniors (mean age = 65.7 years). The exercise program was designed and administered by the subjects following training by an exercise physiologist. The experimenta! subjects, 9 women and 3 men, met one hour each week to exercise, and were encouraged to repeat the exercises at home. A control group matched for age 
and sex participated in the pre- and posttesting sessions but not the exercise program. The content of the exercise program was not specified and although fitness testing was available to the participants at their option, the results were not reported since most subjects did not participate. Response time components were measured using a pursuit tracking task which required the subject to align the pursuit pointer with the appropriate illuminated target light for 200 milliseconds. The latency from the onset of the target light to the beginning of a response in the right direction was labelled correct reaction time. Non-overshoot movement time was the time between the start of a response in the right direction and the beginning of alignment with the target, without overshooting it. Overshoot movement time was the interval between initiation of a response and successful alignment, after overshooting the target. An error score (\% of movements started in the wrong direction) and overshoot score (\% of overshoots per trial) were also calculated. Eight trials, each consisting of 100 movements, were measured before the start of the exercise program and four trials at completion oi the 10 weeks. Measures were analyzed as three blocks of four trials. No significant differences were found between the groups for any of the measures, although significant main effects for blocks were calculated for all measures, indicating a learning effect took place, predominantly between blocks two and three.

Folk dancing was the mode of intervention used in a five week study involving 40 seniors, ages 60 to 94 (Boarman, 1978). Twenty of the subjects (18 women, 2 men) participated in the folk dancing class for one hour twice each week; 20 additional subjects ( 18 women, 2 men) served as controls. Simple reaction and movement time of the right foot was tested for all subjects 
before and after the five week period. Subjects were given 15 trials, 8 of which were used to calculate mean values. No significant difference was found in reaction or movement time following participation in folk dancing.

In one of the earliest training studies involving elderly subjects, Barry et a!. trained five men and three women (mean age $=70$ years) using intermittent exercise on a cycle ergometer, followed by calisthenics, 40 minutes a day, three times per week, for three months (1966a). Simple reaction time was measured by having the subject lift a stylus from a metal plate in response to a light stimulus (Barry, Steinmetz, Page, \& Rodahl, 1966b). The average of five test trials was recorded and the subject was allowed five practice trials before measurements were collected. Movement tests included tests of hand speed (moving a stylus between two metal plates, ten inches apart as fast as possible in 15 seconds) and card sorting (sorting 80 playing cards by color and by suits as fast as possible). Responises ōn thesé and other measures of cardiovascular, motor, and cognitive performance were compared to those of a control group of two men and three women (mean age $=72$ years) who did not participate in the training session. Although the trained subjects demonstrated significant gains in estimated $\mathrm{VO}_{2}$ max, power, muscular strength, and agility, no significant changes were seen in either the experimental or control group for simple reaction time. Significant improvement in sorting cards by suit was seen in the experimental group indicating improved speed of hand movement; no changes were observed in the control group for the hand speed measures.

Roberts (1990) extensively screened her subjects for health problems, excluding those with neurological or muscular diseases and those who were on medication which affected the heart rate (since heart rate was used in 
determining exercise intensity). Physician approval to participate in the training program was also obtained. Male and female subjects volunteered for either the exercise $(n=27$, mean age $=71.8$ years) or control $(n=25$, mean age $=$ 71.8 years) group. Subjects were not different at pretest in health status, diseases, past and present aerobic activity, or miles walked in a week. Measures of simple and choice reaction time and their associated movement times ( 30 trials each) were obtained for all subjects before and after six weeks of training. The exercise group walked three times each week at an intensity of $60-70 \%$ of their age-predicted maximum heart rate. There were no significant differences in reaction or movement time measures before or after the training period between the exercise and control group. In addition, there were no significant differences between the gain scores of the groups for any of the tirning variables.

in a suíssequentit siudy, Whitehurst (1991) also extensively screened potential subjects for health problems. Furthermore, he improved upon Roberts' study by using a longer and slightly more intense training program, and by assessing submaximal $\mathrm{VO}_{2}$ max, although his sample size was substantially smaller. Fourteen women, ages 61-73, completed an extensive medical history, were free of risks for cardiovascular diseases, active in their community, and obtained a medical clearance prior to being randomly assigned to an exercise $(\underline{n}=7)$ or control group $(\underline{n}=7)$. The exercise group met three times each week for eight weeks. They gradually progressed to riding 35 to 40 minutes at 70 $80 \%$ of their predicted maximum heart rate, with a 5-10 minute warm-up and cool-down period. Simple and choice reaction time measures were obtained before and after the training period. The subjects were given 50 trials of each 
(two blocks of 25) following 10 practice trials at each of the testing sessions. A submaximal bike test was used to estimate $\mathrm{VO}_{2} \max$. While estimated $\mathrm{VO}_{2} \mathrm{max}$ significantly increased in the exercise group, and was significantly greater than that measured in the control group following training, no significant differences were seen between the groups before or after training for simple or choice reaction time. Whitehurst suggested "a threshold exists below which reactive ability is impaired and above which reactive ability is maintained" (p. 255). So although exercise may be beneficial in improving reactions of people with circulatory difficulties or below average aerobic capacities, elderly individuals free of disease and living independent and active lives within their communities may not have experienced declines in reaction time. Therefore they may not improve so dramatically.

Dustman et al. (1984) assigned male and female volunteers to an aerobic $(\underline{n}=13$, mean age $=60.6$ years) or strength $(\underline{n}=15$, mean age $=62.3$ years) exercise group, following screening by a physician for health problems that would preclude them from participating in graded exercise testing or the exercise training. A third group of volunteers $(n=15$ mean age $=57.4$ years), also screened (via interview) for health problems, served as controls. Both exercise groups trained one hour a day, three days a week, for four months. The aerobic group used fast walking or slow jogging as the training method, attempting to maintain a heart rate of $70-80 \%$ of their heart rate reserve for increasingly longer durations. All three groups were pre- and posttested on simple and choice reaction time by responding to a stimulus, preceded by a warning sign, on a video screen. For simple reaction time, the subjects were instructed to depress a switch in response to an " $X$ " appearing on the screen. 
Both an " $\mathrm{X}$ " and "O" were presented together for choice reaction time and the subject responded by pressing the left switch when the $X$ was on the left and pressing the right switch when the $X$ was on the right. Fifty trials were obtained for each reaction time measure, with the fastest five and slowest five discarded before calculating the mean. VO2max was measured on a treadmill using a modified Balke protocol for both exercise groups, but not for the control group. $\mathrm{VO}_{2}$ max increased $27 \%$ in the aerobic exercise group and $9 \%$ in the strength group-both significant improvements. A Group (aerobic, strength) by Session (pretest, posttest) ANOVA found a significant interaction for VOzmax. A t-test with change scores indicated the aerobic group increased significantly more than the strength group. The aerobic exercise group also showed a significant decrease in simple reaction time and significant improvement on several other neuropsychological variables, but no significant changes in choice reaction time. Neither the strength nor control group demonstrated significant changes following training on either reaction time measure. The authors speculated that the improved reaction time (as well as significant improvement seen in other neuropsychological tests) in the aerobically trained group may have been due to increased cerebral metabolism.

Panton et al. (1990) also used walk/jog and strength training groups to examine the effects of training on fractionated simple reaction time. Volunteer nonsmoking men and women, free of evidence of coronary artery disease or other contraindications to exercise training and testing, were randomly assigned to an aerobic exercise group ( $\underline{n}=17$, mean age $=71.8$ years), a strength group ( $\underline{n}=20$, mean age $=72.2$ years), and a control group $(\underline{n}=12$, mean age $=72.1$ years). Both training groups met three times a week for six 
months. The aerobic group gradually increased the duration and intensity of exercise until they were walking 40 minutes at $60-70 \%$ of their maximum heart rate reserve. By the 14th week intensity was increased by alternating walk/jog intervals or fast walk/moderate walk intervals until all subjects were exercising 35-45 minutes at $75-85 \%$ of their maximum heart rate reserve. The strength group trained for 30 minutes per session using Nautilus equipment. Before and after the six month training period, all subjects were tested for $\mathrm{VO}_{2}$ max (modified Naughton protocol), strength (two 1RM tests), and total and fractionated reaction time. $\mathrm{VO}_{2} \max$ was significantly greater in the aerobic training group compared to the other two groups following training, having increased $20 \%$; the groups were not significantly different before training. The strength training group increased significantly in strength following training, and was significantly greater in strength compared to the aerobic and control groups (not significantly different prior to training). An analysis of covariance using the pretest scores as the covariate was used to analyze premotor time, motor time, total reaction time and movement time. Comparison of adjusted posttest means of the three groups indicated no significant differences.

Another six month study produced quite different results. Rudisill and Toole (1992) measured simple reaction time, choice reaction time, simple movement time following a simple reaction time task, and choice movement time following a simple reaction time task. Their purpose was to see whether the exercise intervention would prevent the typical age-related decline in these tasks, and to determine whether a time trade-off exists when reaction time and movement time are measured together. Elderly men and women, 64 to 84 years of age, volunteered for either the exercise $(\underline{n}=8)$ or control $(\underline{n}=8)$ group. 
The exercise group participated in cardiorespiratory, flexibility, and strength exercises for one hour three times a week. Analysis of the effect of exercise on the dependent variables using a two by two (group by pretest/posttest) ANOVA revealed a significant interaction for simple reaction time. Simple main effects tests found that simple reaction time slowed for the control group during the six month intervention and that the control group was significantly slower posttest than the exercise group. No significant findings were noted for choice reaction time or the movement time tasks. Another interesting finding of the study was that simple reaction time was significantly faster when it was measured without the movement time tasks. Thus the authors suggest measuring reaction time alone to avoid a task trade-off between reaction time and movement time.

By far the longest training study to date examining the effect of training on reaction time in an elderly population lasted three years (Rikli \& Edwards, 1991). Elderly female subjects volunteered to participate either in an activity class $(\underline{n}=21$; mean age $=70.2$ years) or a nonexercise hobby class $(\underline{n}=13$; mean age $=69.8$ years). Based on a self-report questionnaire, the subjects were determined to be free from any health or physical problems that might interfere with their participation in the exercise program or the tests. Simple and choice reaction times were measured. Subjects were given 4 practice and 10 test trials, with only the last 8 test trials used in calculating scores. The three year training consisted of an activity class that met three times each week for approximately one hour. The content of the class included a warm-up, low impact aerobics, calisthenics and a cool down period. A step test was used as an indirect measure of fitness. At the end of the three year period, choice reaction time improved significantly and simple reaction time improvement 
approached significance in the exercise group. The improvement occurred in the first year of the study (exercise subjects were tested after year one and year three); over the subsequent two years, both simple and choice reaction time remained relatively stable. Similar results were seen in the step test: a significant improvement occurred in year one, but was relatively stable from year one to year three. Comparing pre- and posttest scores of the exercise and control groups revealed that the two groups were significantly different in simple reaction time and the choice reaction time measure approached significance. This was due to the improvements in the exercise group noted above and declines experienced by the control subjects in simple and choice reaction time during the three year period.

\section{Summary}

Several physiological mechanisms to account for the apparent beneficial effect of exercise on psychomotor speed have been proposed by Spirduso $(1982,1980)$ and can be summarized as follows:

1. Exercise may prevent age or disuse related declines in motor neurons or muscle fibers, particularly fast-twitch.

2. Exercise may exert a stimulating effect on the neural pathway involved in movement and may affect the synthesis and maintenance of brain neurotransmitters.

3. Exercise may prevent detrimental structural changes in the nerve cell and loss of dendrites with age.

4. Exercise may assist in the maintenance of hormonal regulatory systems which in turn impact the CNS. 
5. Exercise may maintain blood flow to areas of the brain associated with movement and thus prevent declines in cerebral metabolism.

To evaluate whether more efficient oxygen extraction and transport (as reflected by higher $\mathrm{VO}_{2}$ max values) related to faster psychomotor speed, several investigators calculated correlation coefficients between predicted or directly assessed $\mathrm{VO}_{2}$ max and response time components. Significant relationships between $\mathrm{VO}_{2}$ max and simple reaction time were found by Dzewaltowski (1985) and by Forth and Salmoni (1987), in their 23-24 year old group. Findings were more robust in support of a choice reaction time relationship with $\mathrm{VO}_{2} \max$, with three investigations reporting one or more significant relationship (Dzewaltowski, 1985; Eid et al., 1986; Forth and Salmoni, 1987). Only one study reported a significant relationship between movement time and $\mathrm{VO}_{2} \max$ (Era et al., 1986). Four of the studies reviewed found no relationship between $\mathrm{VO}_{2}$ max and reaction or movemerit time (Chodzko-Zajko \& Ringel, 1987; Fletcher, 1985; Panton et al., 1990; West Virginia University, 1988).

Two studies examined relationships between $\mathrm{VO}_{2}$ max and timing changes pursuant to an exercise program. Dzewaltowski (1985) found no significant correlation between percent changes in $\mathrm{VO}_{2}$ max and fractionated or total reaction time. Panton et al. (1990), however, reported a low but significant relationship between the change in $\mathrm{VO}_{2} \mathrm{max}$ and the change in simple reaction time.

Equally contradictory results were found when examining all training studies. Five of the studies reviewed examined the effect of training on reaction time of subjects of college and middle age (Beise \& Peaseley, 1932; 
Dzewaltowski, 1985; Hascelik et al., 1989; Powell, 1983; Tweit et al., 1963). Two studies reported significant improvements in reaction time measures following training (Hascelik et al., 1989; Tweit et al., 1963). Neither of these studies used a control group therefore attributing any effects to the training is questionable. In fact, of these studies only Beise and Peaseley (1932) included a non-exercise control group, and their intervention involved sports training rather than exercise to improve cardiorespiratory fitness.

Studies involving elderly subjects were more numerous and better controlled, although training intensities were rather low in many instances. Of the 12 studies using elderly subjects, 6 demonstrated significant improvements in simple and/or choice reaction time (Dustman et al., 1984; Dzewaltowski, 1985; Rikli \& Edwards, 1991; Rudisill \& Toole, 1992; Stacey et al., 1985; Vanfraechem \& Vanfraechem, 1977). Three of these studies did not include a non-exercise control group (Dzewaltowski, 1985; Stacey et al., 1985;

Vanfraechem \& Vanfraechem, 1977). Six of the studies using elderly subjects did not find any reaction time changes following exercise participation (Barry et al., 1966b; Boarman, 1978; Normand et al., 1987; Panton et al., 1990; Roberts, 1990; Whitehurst, 1991). All of these studies included non-exercise control subjects.

Movement time was considered in six studies, all involving elderly subjects (Barry et al., 1966b; Boarman, 1978; Normand et al., 1987; Panton et al., 1990; Roberts, 1990; Rudisill \& Toole, 1992). Only Barry et al. reported a significant improvement in movement time, measured by a card-sorting task rather than following a reaction time task, as is more common. 


\section{Chapter 3}

\section{Methodology}

Introduction

The purpose of this research was to examine the effect of aerobic exercise on simple and discrimination reaction time and movement time of middle-aged women. The study examined the effect of one independent variable, aerobic exercise, on five dependent variables: simple reaction time, movement time following simple reaction time, discrimination reaction time, movement time following discrimination reaction time, and estimated $\mathrm{VO}_{2} \mathrm{max}$. In this chapter, characteristics of the subjects, the instrumentation, the measurement procedures, the training procedures, and the statistical analyses are detailed.

\section{Subject Selection}

Subjects for this study were 15 normally active women between the ages of 34 and 46 years. Subjects volunteered for either the exercise $(\underline{n}=8)$ or control group $(n=7)$. Subjects were solicited from the students, faculty, and staff at San Jose State University, and from businesses located in the surrounding area of San Jose, California. Inducement for the exercise group was the participation in a free, structured exercise program. Control group participants benefited from a free fitness evaluation and personal training sessions at the conclusion of the research. 
Each subject was required to meet the following criteria, as determined by responses to a health history questionnaire (Appendix $A$ ):

1. female nonsmoker between 34 and 46 years of age at the commencement of pretest procedures.

2. participation in aerobic exercise for no more than one hour a week at moderate intensity (rating of perceived exertion of 12 on the Borg scale) or greater for the six months preceding the pretest.

3. apparently healthy as defined by the American College of Sports Medicine; that is, free of major symptoms or signs of cardiopulmonary and metabolic diseases, and exhibiting no more than one major coronary risk factor $(1991$, p. 6).

4. a body mass index (BMI) of less than $27.3 \mathrm{~kg} / \mathrm{m}^{2}$. A significant increase in risk is associated with a BMl of $27.3 \mathrm{~kg} / \mathrm{m}^{2}$ and higher for women (American College of Sports Medicine, 1991).

5. able to drive an automobile.

Testing and training procedures, potential risks and benefits of participation, as well as rights of participants, were discussed with the volunteers, and informed consent was obtained from all subjects prior to the commencement of the study (Appendix B). An identification number (ID \#) was 
assigned to the subject upon acceptance to the study; that number was noted on the subject's informed consent form. All consent and health history forms were maintained by the researcher in a locked file. The subject's ID \# was used on all data collection sheets to protect confidentiality.

\section{Instrumentation}

Reaction Time and Movement Time. Simple and discrimination reaction time and movement time were measured using a Lafayette Reaction/Movement Timer, model 63017, consisting of a control panel and a stimulus unit. The Experimenter could control the stimulus (red, green, and biue iights or $32.8 \mathrm{~Hz}$ Sonalert) and the time between the warning light and the stimulus light (1-10 seconds) from the control panel. Two Start Switch Pads with depressable foot pedals mounted in the center (model 63510A) were attached to the Reaction/Movement Timer and activated and deactivated two clocks on the control panel. The clocks measured time to the nearest millisecond and ranged from .001 to 9.999 seconds.

\section{Pre- and Posttesting Measurement Procedures}

Introduction. Prior to being admitted to the study, subjects were screened for prior physical activity and health problems that would preclude them from participating in exercise testing and/or exercise training. An informed consent form (Appendix B) was obtained from all subjects prior to the commencement of the testing procedures. The pre- and posttest procedures lasted approyimately two hours. Anthropometric and timing measurements were obtained first, followed by $\mathrm{VO}_{2}$ max estimation. Between the pre- and posttest, the exercise 
group participated in an aerobic exercise training program for 10 weeks while the control group maintained their normally active lifestyle for the 10 week period between tests. All pre- and posttests took place at the San Jose State University Exercise Physiclogy and Biomechanics Lab and the San Jose State University track.

Subjects were asked to report to the Lab in a postabsorptive state (having refrained from eating and consuming carbonated or caffeinated beverages for at least two hours prior to testing). Subjects were instructed to wear (or bring) comfortable clothing, including shorts and comfortable walking shoes.

Body Composition and Size. Anthropometric measures were determined by measuring height in centimeters with a wall scale utilizing a Broca plane, and body mass in kilograms on a platform scale. Body fat was assessed as the sum of skinfold measures taken at five sites: tricep, subscapula, suprailiac, abdomen, and thigh (McArdle, Katch, \& Katch, 1991). Measurement techniques followed recommendations by Heyward (1991). The five sites were marked and measured, in a rotational order, to the nearest .5 millimeter using a Lange Skinfold Caliper. Two measurements were obtained at each site with additional measures obtained if these values differed by greater than 1 millimeter. Measurements were recorded on the Summary Data Sheet (Appendix D) and the average of the two values was calculated and used as the skinfold thickness at each site.

Reaction and Movement Time. The protocol selected for measuring simple and discrimination reaction and movement time was similar to that used by Baylor and Spirduso (1988). This protocol was selected for the following 
reasons: (1) the training mode principally involved muscles of the lower body so response time measures for the leg rather than the arm were appropriate and (2) the protocol was similar to braking situations when driving an automobile therefore the learning effect would be minimized.

Subjects were seated in a chair facing the stimulus unit, adjusted to eye level and one meter away (as measured from eyes to stimulus unit), arms resting in the lap, with the right lower leg at approximately 30 degrees of flexion when depressing the right foot pedal. The Switch Pads were placed on the floor with the center of the foot pedals 28 centimeters apart. Both the chair and the switch pads were centered with respect to the stimulus unit. When the Experimenter indicated "Ready," subjects depressed the right Switch Pad with the right foot. A warning light flashed followed by an interval of varying length (3-5 seconds). A red stimulus light was activated for the simple response time condition. Subjects were instructed to respond as quickly as possible to the red light by lifting the right foot from the right foot pedal and depressing the left foot pedal. The foreperiod interval was randomly varied to reduce poiential anticipation of the stimulus.

For discrimination response time, the procedure was similar excepi that subjects were presented with either a red light stimulus or a green light stimulus, in a random order. When presented with a red stimulus the subject was instructed to respond in the same manner described for simple reaction time. When presented with a green light the subject was instructed not to respond, but to maintain depression on the accelerator switch and wait for the next warning light. Subject errors (i.e., responding to the green light) were 
replaced with another trial, with the error being recorded. Standardized instructions, read to subjects prior to testing, are provided in Appendix F.

Subjects were administered two blocks of 30 trials for the simple condition and two blocks of 60 trials ( 30 red and 30 green) for the discrimination condition. The number of blocks and trials were similar to that previously used by Baylor and Spirduso (1988). Subjects were allowed a three minute rest period between blocks. The order of testing simple and discrimination response time was counterbalanced across subjects so that approximately half the subjects began with simpie and hali with discrimination. The randomized foreperiod interval was varied from three to five seconds. Reaction times and response times, as measured by the Reaction/Movement Tirner, were recorded on the Response Time Data Sheet (Appendix C). Movement time was subsequently calculated by subtracting reaction time from response time.

To assess the effect of learning, the reaction and movement time trials for each condition were blocked into six groups of ten trials and a mean was calculated for each block. An analysis of variance between blocks was calculated to determine whether the blocks differed significantly from each other. No significant difference $(\underline{p}<.05)$ for blocks was found for any of the timing variables. Thus each subject's simple and discrimination reaction and movement time scores were calculated as the mean of all 60 trials.

VO2max Estimation. The Rockport fitness walking test was used to estimate VO2max (Rockport Walking Institute, 1986). The walking test took piace at the San Jose State University track following completion of the timing tests. The subjects warmed up with approximately five minutes of light stretching and were then instructed to walk one mile on a measured track as 
fast as possible. Participants were encouraged to maintain a steady pace and were stopped if they ran. The researcher timed the one mile walk to the nearest second. Immediateiy upon the conclusion of the walk, the researcher counted the subject's pulse for 15 seconds by palpation of the radial artery. This count was multiplied by four to obtain the heartrate in beats per minute (bpm). The subject was then instructed to cool down by walking slowly and stretching.

$\mathrm{VO}_{2}$ max was estimated from the walk using the following equation:

VO2max $(\mathrm{ml} / \mathrm{kg} / \mathrm{min})=132.853-0.0769^{*}$ Weight $(\mathrm{lbs})-0.3877$ * Age (years) $-3.2649^{*}$ Time $-0.1565^{*} \mathrm{HR}$

where HR is heart rate in beats per minute (bpm) at the end of the walk and TIME is mile walk time. This test and generalized equation was developed and validated by Kline et al. using men and women ages 30-69 years (1987). The correlation and SEE with the criterion measure $\mathrm{VO}_{2}$ max measured on a treadmill) was $\underline{r}=.88$ and $5.0 \mathrm{ml} / \mathrm{kg} / \mathrm{min}$. A subsequent analysis of this test using female subjects, ages 30-39 years, reported a correlation and SEE of $r=$ .73 and $4.57 \mathrm{mi} / \mathrm{kg} / \mathrm{min}$ (Zwiren, Freedson, Ward, Wilke, \& Rippe, 1991). Values and calculations were recorded on the subject's Summary Data Sheet (Appendix D).

\section{Training Procedures}

The training period commenced following completion of pretesting. To address the question of whether changes in response time components were associated with changes in fitness level, as measured by estimated VO2max, the intervention program was designed to elicit a significant increase in VO2max. Therefore, American College of Sports Medicine (1991) guidelines 
for improvement in cardiorespiratory fitness and results of previous training studies were reviewed in the design and administration of the exercise program (Cowan \& Gregory, 1985; Flint, Drinkwater, \& Horvath, 1974; Jette, Sidney, \& Campbeil, 1988).

Current ACSM guidelines for developing and maintaining cardiorespiratory fitness recommend participating in activities using large muscle groups, rhythmic and continuous in nature, three to five days per week, at an intensity of $60-90 \%$ of maximum heart rate or $50-85 \%$ of heart rate reserve for 20 to 60 minutes (American College of Sports Medicine, 1991). Training studies using walking as the mode of exercise and lasting between 6 to 12 weeks have been successful in eliciting significant improvements in VO2max of middle-aged men and women (Cowan \& Gregory, 1985; Flint et al., 1974; Jette et al., 1988). A review of these studies indicated an intensity of between 60 and $90 \%$ of maximum heart rate and a frequency of three to four times weekly were employed. Based on these results, a 10 week walking and/or jogging program with participants exercising at between 60 and $90 \%$ of predicted maximum heart rate three to four days per week was deemed sufficient to produce a measurable improvement in $\mathrm{VO}_{2}$ max.

Participants in the exercise group were asked to attend three training sessions per week, supervised by the experimenter at SJSU facilities.

Additionally, subjects were asked to train one day each week on their own, thus completing four training sessions per week. During the first week of training subjects were taught to take a 10 second exercise heart rate by palpation of the carotid or radial artery. They were also instructed how to use the Borg Scale for estimating their level of perceived exertion (Appendix E). 
Each workout was preceded by a warm-up of slow walking or jogging and light stretching. Workouts were followed by a cool-down period in which subjects gradually slowed the pace of their workout to a slow walk and finnished with stretching exercises. The workout consisted of continuous fast walking for a prescribed period of time at a pace to elicit a heart rate of between 60 and $90 \%$ of the subject's age-predicted maximum heart rate. Two of the exercise subjects combined slow jogging and fast walking to obtain the required target heart rate. Individualized workouts were developed based on the subjects' pretest estimated $\mathrm{VO}_{2}$ max. All subjects began at a minimum of 30 minutes continuous exercise. The duration was increased by five minutes every one to three weeks based on the subject's ratings of perceived exertion (RPE) and discussion of any physical difficulties experienced (i.e., sore muscles). The duration was increased until the subject was exercising continuously for 50 minutes, excluding the warm-up and cool-down. This duration was then maintained for the remainder of the 10 week program. All subjects were completing 50 continuous minutes of exercise by the 10th week of the program. Subjects were asked to take a 10 second pulse count and estimate their RPE midway and at the completion of each workout. These were recorded on workout logs maintained by the experimenter for each subject. Subjects were also given a sheet on which to record their unsupervised workouts, which were transferred to the workout logs by the subjects each week. Participants in the exercise program were required to complete $75 \%(30)$ of the training sessions for their data to be included in the final analysis. At this threshold subjects would be exercising on average three days per week which meets the ACSM minimum requirements discussed above. One subject who completed the 10 
week program did not meet the threshold and therefore her data were excluded from the analyses. Those subjects meeting the minimum requirements completed an average of 33 (out of 40 ) workout sessions (82.5\%). An average of 25 (out of 30 possible) of these were supervised and 8 (out of 10 possible) unsupervised.

\section{Statistical Analysis}

This study examined the effect of one independent variable, aerobic exercise, on five dependent variables: simple reaction time (SRT), movement time following simple reaction time (SMT), discrimination reaction time (DRT), movement time following discrimination reaction time (DMT), and estimated VO2max.

An Analysis of Covariance (ANCOVA) was selected to statistically control initial differences between the exercise and control groups which might confound posttest differences between them. Tests for homogeneity of regression indicated parallel regression slopes for pretest estimated $\mathrm{VO}_{2} \mathrm{max}$, SMT, DRT, and DMT therefore these dependent variables were analyzed using simple ANCOVA, with the appropriate pretest value used as a covariate. Pretest SRT violated tests of homogeneity of variance and homogeneity of regression. Therefore it was analyzed with the nonparametric Mann-Whitney $\underline{U}$ test using gain scores calculated from pre- and posttest SRT for each group.

Pearson Product Moment Correlations (PPMC) were calculated to determine the relationship between estimated VO2max and SMT, DRT and DMT, as well as the relationship between changes in estimated $\mathrm{VO}_{2}$ max and changes in these variables. The nonparametric Spearman rank-difference 
method was used to examine the relationship between estimated VO2max and SRT, and between the change in estimated VO2max and the change in SRT. The level of significance for rejection or acceptance of the null hypotheses for all calculations was set at the .05 level of significance. 


\section{Chapter 4}

\section{Results and Discussion}

The purpose of this research was to examine the effects of a 10 week aerobic exercise program on estimated $\mathrm{VO}_{2}$ max, simple reaction time (SRT), movement time following simpie reaction time (SMT), discrimination reaction time (DRT), and movement time following discrimination reaction time (DMT). Data were analyzed using SPSS software. In this chapter the results are presented and discussed.

\section{Results}

Fifteen female volunteers, ages 34 to 46 years, participated in the research. The exercise group $(n=8)$ completed 10 weeks of training between the pretest and the posttest while the control group $(\underline{n}=7)$ maintained a normally active lifestyle. Descriptive characteristics for both groups are presented in Table 1.

A simple ANCOVÁ was employed to test the null hypotheses that no significant differences between adjusted posttest means of the exercise and control groups existed for estimated VOzmax, SMT, DRT, and DMT. For SRT, changes between pre- and posttest for the exercise versus control group were analyzed using the nonparametric Mann-Whitney $\underline{U}$ test. Significant differences between the exercise and control group were found for estimated $\mathrm{VO}_{2} \mathrm{max}$, $\underline{E}(1,12)=6.17, \underline{p}<.05$, and for $D M T, E(1,12)=5.92, \underline{p}<.05$. Examination of the 
Table 1

Descriptive Characteristics of Exercise and Control Group

\begin{tabular}{|c|c|c|c|c|}
\hline \multirow[t]{2}{*}{ Descriptive Variable } & \multicolumn{2}{|c|}{ Exercise $(n=8)$} & \multicolumn{2}{|c|}{ Control $(n=7)$} \\
\hline & $\underline{M}$ & $\underline{\mathrm{SD}}$ & $\underline{M}$ & $\underline{S D}$ \\
\hline \multicolumn{5}{|l|}{ Age (years) } \\
\hline Pretest & 39.68 & 3.58 & 42.18 & 4.38 \\
\hline Posttest & 39.89 & 3.59 & 42.41 & 4.38 \\
\hline \multicolumn{5}{|l|}{ Height (cm) } \\
\hline Pretest & 163.80 & 5.65 & 161.41 & 9.75 \\
\hline Posttest & 163.59 & 5.91 & 161.36 & 10.28 \\
\hline \multicolumn{5}{|l|}{ Weight $(\mathrm{kg})$} \\
\hline Pretest & 65.51 & 6.62 & 62.03 & 10.82 \\
\hline Posttest & 63.95 & 6.77 & 62.41 & 10.99 \\
\hline \multicolumn{5}{|l|}{ Sum of 5 Skinfolds $(\mathrm{mm})$} \\
\hline Pretest & 140.81 & 23.54 & 126.04 & 33.73 \\
\hline Posttest & 126.03 & 23.20 & 129.00 & 35.32 \\
\hline \multicolumn{5}{|l|}{ One Mile Walk Time (min) } \\
\hline Pretest & 13.85 & 0.67 & 14.67 & 2.10 \\
\hline Posttest & 12.69 & 1.15 & 14.55 & 2.22 \\
\hline \multicolumn{5}{|c|}{ Heartrate After Walk Test (bpm) } \\
\hline Pretest & 156.00 & 16.84 & 148.57 & 18.96 \\
\hline Posttest & 158.50 & 15.11 & 144.57 & 16.24 \\
\hline
\end{tabular}


practical significance of these results found that for estimated VO2max and DMT, respectively, 26 and $25 \%$ of the difference between the exercise and control group was accounted for by the treatment (Tolson, 1980). A summary table for the ANCOVAs and a table of means are presented in Tables 2 through 5 for estimated VO2max, SMT, DRT, and DMT. Pre- and posttest means and results of the Mann-Whitney $\underline{U}$ test for SRT are presented in Table 6.

To determine if any significant relationships existed between estimated VO2max and the timing variables, correlation coefficients were calculated using the Pearson product-moment method between (1) pretest estimated VO2max and pretest SMT, DRT, and DMT (2) posttest estimated VO2max and posttest SMT, DRT, and DMT and (3) changes in estimated VO2max and changes in SMT, DRT, and DMT. The same comparisons were made between estimated $\mathrm{VO}_{2} \max$ and SRT using the Spearmari rank-difference correlation method. A significant negative correlation was found between pretest estimated $\mathrm{VO}_{2} \mathrm{max}$ and DRT, $\underline{r}=-.5308, \underline{\mathrm{D}}<.05$. A significant negative correlation was also revealed between posttest estimated VO2max and DMT, $\underline{r}=-.6072, \underline{p}<.05$. Calculation of the coefficient of determination found that $28 \%$ of the variance in DRT could be accounted for by pretest estimated VO2max and that $37 \%$ of the variance in DMT could be accounted for by posttest estimated VO2max. Correlation coefficients between estimated $\mathrm{VO}_{2}$ max and the timing variables are presented in Table 7. 
Table 2

Table of Means and Summary Analysis of Covariance

For Estimated $\mathrm{VO}_{2} \max$

Table of Means

\begin{tabular}{|c|c|c|c|c|c|}
\hline \multirow[b]{3}{*}{ Group } & & & \multicolumn{3}{|c|}{ Posttest } \\
\hline & \multicolumn{2}{|c|}{ Pretest } & \multicolumn{2}{|c|}{ Observed } & \multirow{2}{*}{$\begin{array}{c}\text { Adjusted } \\
M \\
\end{array}$} \\
\hline & $\underline{\underline{M}}$ & $\underline{S D}$ & $\underline{M}$ & $\underline{S D}$ & \\
\hline Exercise & 36.74 & 4.15 & 40.31 & 4.21 & 39.31 \\
\hline Control & 34.85 & 6.34 & 35.70 & 7.41 & 36.69 \\
\hline
\end{tabular}

Note. Values are in $\mathrm{ml} / \mathrm{kg} / \mathrm{min}$.

Summary Analysis of Covariance

\begin{tabular}{lcrrrr}
\hline Source & $\underline{65}$ & df & MS & E & $\underline{\underline{p}}$ \\
\hline Group & 24.75 & 1 & 24.75 & $6.17^{*}$ & .029 \\
Error & 48.10 & 12 & 4.01 & & \\
Total & 72.85 & 13 & & & \\
\hline " D<.05. & & & & &
\end{tabular}


Table 3

Table of Means and Surnmary Analysis of Covariance

For SMT

Table of Means

\begin{tabular}{|c|c|c|c|c|c|}
\hline \multirow[b]{3}{*}{ Group } & & & \multicolumn{3}{|c|}{ Posttest } \\
\hline & \multicolumn{2}{|c|}{ Pretest } & \multicolumn{2}{|c|}{ Observed } & \multirow{2}{*}{$\begin{array}{c}\text { Adjusted } \\
\underline{M}\end{array}$} \\
\hline & $\underline{M}$ & $\underline{S D}$ & M & $\underline{\mathrm{SD}}$ & \\
\hline Exercise & 254 & 51 & 233 & 47 & 241 \\
\hline Control & 273 & 72 & 268 & 62 & 261 \\
\hline
\end{tabular}

Note. Values are in msec.

Summary Analysis of Covariance

\begin{tabular}{lrrrrr}
\hline Source & $\underline{\text { SS }}$ & $\underline{\text { df }}$ & $\underline{M S}$ & $\underline{F}$ & $\underline{p}$ \\
\hline Group & $1,372.67$ & 1 & $1,372.67$ & 2.43 & .145 \\
Error & $6,773.86$ & 12 & 564.49 & & \\
Total & $8,146.53$ & 13 & & & \\
\hline
\end{tabular}


Table 4

Table of Means and Summary Analysis of Covariance For DRT

Table of Means

\begin{tabular}{|c|c|c|c|c|c|}
\hline \multirow[b]{3}{*}{ Group } & & & \multicolumn{3}{|c|}{ Posttest } \\
\hline & \multicolumn{2}{|c|}{ Pretest } & \multicolumn{2}{|c|}{ Observed } & \multirow{2}{*}{$\begin{array}{c}\text { Adjusted } \\
\underline{M}\end{array}$} \\
\hline & $\underline{M}$ & $\underline{S D}$ & $\underline{M}$ & $\underline{S D}$ & \\
\hline Exercise & 487 & 46 & 516 & 60 & 549 \\
\hline Control & 555 & 87 & 586 & 86 & 552 \\
\hline
\end{tabular}

Note. Values are in msec.

Summary Analysis of Covariance

\begin{tabular}{lrrrrr}
\hline Source & \multicolumn{1}{c}{$\underline{\mathrm{SS}}$} & $\underline{\text { df }}$ & $\underline{\mathrm{MS}}$ & $\underline{\mathrm{F}}$ & $\underline{\mathrm{p}}$ \\
\hline Group & 35.59 & 1 & 35.59 & .04 & .849 \\
Error & $11,237.78$ & 12 & 936.48 & & \\
Total & $11,273.37$ & 13 & & & \\
\hline
\end{tabular}


Table 5

Table of Means and Summary Analysis of Covariance

For DMT

Table of Means

\begin{tabular}{|c|c|c|c|c|c|}
\hline \multirow[b]{3}{*}{ Group } & & & \multicolumn{3}{|c|}{ Posttest } \\
\hline & \multicolumn{2}{|c|}{ Pretest } & \multicolumn{2}{|c|}{ Observed } & \multirow{2}{*}{$\begin{array}{c}\text { Adjusted } \\
\mathrm{M}\end{array}$} \\
\hline & $\underline{M}$ & $\underline{S D}$ & M & $\underline{S D}$ & \\
\hline Exercise & 279 & 52 & 248 & 50 & 252 \\
\hline Control & 290 & 75 & 293 & 63 & 289 \\
\hline
\end{tabular}

Note. Values are in msec.

Summary Analysis of Covariance

\begin{tabular}{|c|c|c|c|c|c|}
\hline Source & $\underline{\text { SS }}$ & $\underline{\mathrm{df}}$ & MS & $\underline{E}$ & $\underline{p}$ \\
\hline Group & $4,881.77$ & 1 & $4,881.77$ & $5.92^{*}$ & .032 \\
\hline Error & $9,895.32$ & 12 & 824.61 & & \\
\hline Total & $14,777.09$ & 13 & & & \\
\hline
\end{tabular}


Table 6

Table of Means and Mann-Whitney $\underline{U}$ Test

For SRT

Table of Means

\begin{tabular}{|c|c|c|c|c|c|c|}
\hline \multirow[b]{2}{*}{ Group } & \multicolumn{2}{|c|}{ Pretest } & \multicolumn{2}{|c|}{ Posttest } & \multicolumn{2}{|c|}{ Change } \\
\hline & $\underline{M}$ & $\underline{S D}$ & $\underline{M}$ & $\underline{S D}$ & $\underline{\mathrm{M}}$ & $\underline{S D}$ \\
\hline Exercise & 394 & 23 & 430 & 60 & 36 & 44 \\
\hline Control & 405 & 55 & 424 & 40 & 19 & 35 \\
\hline
\end{tabular}

Note. Values are in msec.

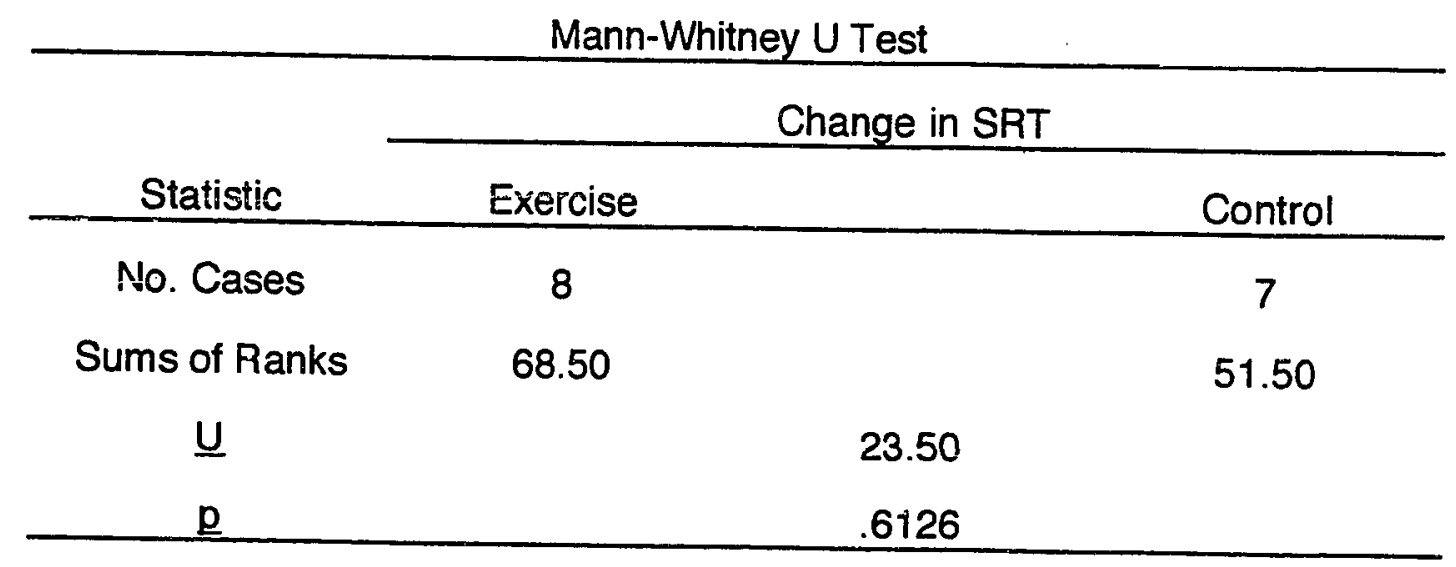


Table 7

Correiations Between Estimated $\mathrm{VO}_{2} \max$

and Timing Variables

\begin{tabular}{lccc}
\hline $\begin{array}{l}\text { Timing } \\
\text { Variable }\end{array}$ & $\begin{array}{c}\text { Pretest } \\
\text { VO2max }\end{array}$ & $\begin{array}{c}\text { Change in } \\
\text { VO2max }\end{array}$ & Posttest VO2max \\
\hline SRTa & .1646 & .1877 & .0321 \\
SMTb & -.3913 & .1007 & -.4613 \\
DRTb & $-.5308^{*}$ & -.0301 & -.4777 \\
DMTb & & & \\
\hline
\end{tabular}

a Calculated using Spearman rank-difference correlation method.

b Calculated using Pearson product-moment correlation method.

* Significant at $\underline{p}<.05$. 


\section{Discussion}

Two hypotheses were investigated in this study. The null hypothesis stating no significant differences between adjusted posttest ineans would occui was accepted for three of the five dependent variables: simple reaction time, movement time following simple reaction time, and discrimination reaction time. The null hypothesis was rejected for estimated VO2max, $E(1,12)=6.17, p<.05$, and for movement time following discrimination reaction time (DMT), $E(1,12)=$ 5.92, $\mathrm{p}<.05$.

The 10 week exercise program was effective in improving the cardiorespiratory fitness of the exercise group, as evidenced by a $10 \%$ improvement in observed $\mathrm{VO}_{2}$ max. Although the control group improved as well, the adjusted posttest mean of the exercise group was significantly greater. The $2 \%$ increase in observed $\mathrm{VO}_{2}$ max in the control group is attributed to two factors: (1) the exercise program took place during summer months when people tend to be more active and (2) practice effects. Additional evidence of the effectiveness of the exercise program can be seen in changes in the sum of five skinfolds (Table 1). The exercise group decreased an average of $14.78 \mathrm{~mm}$ while the control group increased an average of $2.96 \mathrm{~mm}$.

The significant difference between the exercise and control group for adjusted posttest means of DMT was somewhat surprising. Barry et al. (1966b) repcrted significant improvement on a task measuring movement speed by card-sorting. However, more traditiona! methods of measuring movement time (i.e., following a reaction time task) have not shown evidence of a training effect (Boarman, 1978; Normand et al., 1987; Panton et al., 1990; Roberts, 1990; Rudisill \& Toole, 1992). One possible explanation is that these studies, with the 
exception of Boarman, measured movement speed of the upper extremity while training involved primarily, if not exclusively, the lower body. Boarman measured movement time of the right foot following a simple reaction time task and found no significant changes following five weeks of folk dancing. The training protocol in the present study was twice as long and more intense than Boarman's. Therefore it was more likely to affect lower leg musculature than folk dancing twice a week. Adaptations to training that may affect movement speed include increased levels of myofibrilar adenosinetriphosphate (myosin ATPase), creatine phosphokinase (CPK), and myokinase (MK) (Fox, Bowers, \& Foss, 1989). The presence of the enzyme myosin ATPase speeds up the breakdown of ATP while the enzymes CPK and MK are important in rapidly regenerating ATP. Adaptations are specific to the muscle groups involved in exercise, thus evaluation of movement time should be specific to the musculature involved as well. Evidence that muscular adaptations occurred in the exercise group is present when $\mathrm{VO}_{2}$ max changes are examined independent of weight changes. $\mathrm{VO}_{2}$ max in liters per minute (L/min) increased in the exercise group from a mean of $2.40 \mathrm{~L} / \mathrm{min}$ pretest $(\underline{S D}=.28)$ to a mean of $2.57 \mathrm{~L} / \mathrm{min}$ posttest $(\underline{\mathrm{SD}}=.29)$, a $7 \%$ increase. Research examining the differential effect of training on movement speeci of the upper and lower extremities is needed to further evaluate this finding.

Another possible explanation for the faster DMT times observed in the exercise group is a task time trade-off. Rudisill and Toole (1992) found reaction time to be significantly faster when not followed by a movement time task. They suggest that a trade-off may exist whereby reaction time is slowed to increase movement speed or vice versa. Some evidence exists for such a trade-off when 
correlational results of the present study are reviewed (Table 7). Pretest $\mathrm{VO}_{2}$ max was significantly correlated with DRT but posttest $\mathrm{VO}_{2}$ max was significantly correlated with DAT. Further support for a trade-off is provided when examining changes in total response time and its components. Pretest DRS ( $\underline{M}=766 \mathrm{msec}$ ) was essentially unchanged following the training study ( $\underline{M}$ $=764 \mathrm{msec}$ ) in the exercise group. However DRT increased from a pretest mean of $487 \mathrm{msec}$ to a posttest mean of $516 \mathrm{msec}$, an increase of $29 \mathrm{msec}$. Mean DMT decreased from $279 \mathrm{msec}$ pretest to $248 \mathrm{msec}$ posttest, a decrease of 31 msec. A somewhat similar, though nonsignificant, trend was apparent in simple response time in the exercise group: mean reaction time increased 36 msec from pre- to posttest while mean movement time decreased by $21 \mathrm{msec}$.

Of note is that this apparent trade-off occurred only in the exercise group. The control group's DRT increased by an average of $31 \mathrm{msec}$ while DMT remained essentially unchanged from pre- to posttest. This may be due to a iengthening of the motor time component of reaction time in the exercise group. Kroll and Clarkson (1978) found that when examining fractionated response time in a resisted versus unresisted condition, total reaction time increased, due to an increase in motor time, while movement time decreased. The resisted condition consisted of applying additional resistance to the subject's heel in a knee extension movement. Although the trade-offs between motor time and movement time observed by Kroll and Clarkson occurred in both active and inactive subjects, the same resistance was added for both groups ( $10 \%$ of isometric knee extension strength). The possibility exists that an increase in muscle mass of the lower extremity in the exercise group acted as additional resistance thereby resulting in an increase in reaction time due to increased 
motor time, and a decreased movement time similar to that observed by Kroll and Clarkson. However, large increases in muscle mass would not typically be expected in an endurance training program (McArdle, Katch, \& Katch, 1991). Thus the question remains: why would participation in 10 weeks of aerobic exercise lead to a trade-off between reaction time and movement time in the exercise group? Further research is warranted to address this question by examining the effects of training on the fractionated components of response time. The response time measure obtained should be specific to the musculature trained, as was the case in the present research.

The lack of significant findings with respect to simple and discrimination reaction time suggest that a 10 week exercise program is not sufficient to improve CNS efficiency. This is in agreement with several studies of similar duration (Barry et al., 1966b; Boarman, 1978; Normand et al., 1987; Roberts, 1990; Whitehurst, 1991). Studies lasting 12 or fewer weeks that reported significant improvements in reaction time did not include a non-exercise control group therefore attributing changes to training is questionable (Dzewaltowski, 1985; Hascelik et al., 1989; Tweit et al., 1963; Vanfraechem \& Vanfraechem, 1977). Research lasting from four months to three years generally supported a training effect (Dustman et al., 1984; Rikli \& Edwards, 1991; Rudisill \& Toole, 1992; Stacey et al., 1985). Only Panton et al. (1990) found no training effect. Therefore the duration of the exercise program in the present study, although sufficient to produce $\mathrm{VO}_{2} \mathrm{max}$ improvement, may not have been long enough to evoke central nervous system adaptations. The descriptive studies, which are far more robust in support of a relationship between exercise and response time components, typically define their "active" subjects as people who have been 
active at least two to three years (Baylor \& Spirduso, 1988; Spirduso, 1975;

Spirduso \& Clifford, 1978). Additionally, the subjects in this study were relatively well-fit to begin. The pretest mean $\mathrm{VO}_{2}$ max values for toth groups were considered "good" according to American Heart Association classifications based on age and sex (1972). Both Whitehurst (1991) and Panton et al. (1990) suggest that there may be some minimal threshold for $V_{2}$ max which is sufficient to maintain psychomotor speed. Thus exercise may only be able to improve reaction time in those people who have experienced declines. Subjects, such as those in this study, who are healthy and normally active and whose $\mathrm{VO}_{2}$ max has not deteriorated may not be able to improve reaction time. They may only be able to prevent future declines. The role of exercise in preventing declines in psychomotor speed may be a more appropriate avenue of research than the more numerous short term studies which can only evaluate improvement.

Another possible explanation for no significant changes in reaction time may be the task time tradeoffs previously discussed. The increases in simple and discrimination reaction time observed in the exercise group may be due to lengthening of motor time corresponding to faster movement times (the tradeoff). Because reaction time in this study was not fractionated into a premotor and motor time component there was no way to determine whether the increase observed in simple and discrimination reaction time was due to a lengthening of the central premotor time component or the peripheral motor time component. Future research evaluating the effect of exercise on reaction time should measure reaction time by itself rather than followed by a movement time task, as suggested by Rudisill and Toole (1992), unless fractionated reaction time is 
measured with movement time. Examining the effect of exercise on frac:ionated reaction time and movement time would enable the researcher to examine separately the effect of exercise on central and peripheral components of response time, and where task time trade-offs occur.

The second hypothesis addressed in this study stated that no significant relationships between $\mathrm{VO}_{2}$ max and the timing variables would exist. The null hypothesis was rejected for pretest VO2max and pretest DRT, and for posttest VO2max and posttest DMT, $\mathbf{p}<$.05. The significant correlation between components of discrimination response time and VO2max, both pre- and posttest, indicates that fitness is an important contributor to psychomotor speed, especially in more complex tasks requiring greater central processing time. The importance of fitness to both central (reaction time) and peripheral (movement time) components of response time is evident from the significant relationship of DRT to VO2max pretest and the significant relationship of DMT to VO2max posttest.

The significant relationship calculated between DMT and VO2max in the present study was unexpected since a similar relationship has been previously reported in only one study (Era et al., 1986). However, as discussed above, this may be because movement time was frequently assessed using the upper extremity while training focused on lower body musculature. The task-related trade-off between reaction time and movement time suggested above appears to be the explanation for the switch in the significant relationship between $\mathrm{VO}_{2} \mathrm{max}$ and discrimination reaction time pretest to a significant relationship between $\mathrm{VO}_{2} \max$ and discrimination movement time posttest. 
Changes in $\mathrm{VO}_{2}$ max were unrelated to changes in reaction or movement time. This was not surprising since increased $\mathrm{VO}_{2}$ max represents an improvement in the ability of the musculature involved to take up and vitilize oxygen, rather than that of the brain.

The lack of a consistently strong relationship between $\mathrm{VO}_{2}$ max and response time components in this and other studies, and the small portion of the variance in these measures accounted for by $\mathrm{VO}_{2} \mathrm{max}$, indicates that other factors are important in the prediction of reaction and movement time. $\mathrm{VO}_{2} \mathrm{max}$ is higher in people who exercise but many other factors such as blood pressure, cholesterol levels, eating, drinking and smoking habits, and stress are also different in the exercising population. An index such as that developed by Chodzko-Zajko and Ringel (1987) that includes different variables affected by exercise and known to affect reaction time may be more useful than $\mathrm{VO}_{2} \mathrm{max}$ alone, and more susceptible to change pursuant to increased physical activity. Further, measuring these variables and response time components periodically throughout the training period may help to identify when adaptations cccur, and to what degree the various physiological and psychological measures contribute to any adaptations. 


\section{Chapter 5}

\section{Conclusions}

\section{Summary}

The purpose of this study was to examine the effect of aerobic exercise on simple and discrimination reaction and movement time in middle-aged women. Fifteen women between the ages of 34 and 46 participated in this research. They volunteered for either the control $(n=7)$ or exercise $(n=8)$ group. Following measurement of simple and discrimination reaction time and movement time and a one mile walk test to estimate $\mathrm{VO}_{2} \max$, the exercise group participated in a 10 week continuous walking and/or jogging program. The control group maintained their normally active lifestyle during this period. SPSS software was used for the statistical analysis. Posttest means, adjusted for pretest differences, were significantly different between the two groups for estimated $\mathrm{VO}_{2} \max$ and for discrimination movement time, $\underline{\mathrm{p}}<.05$. Differences between the adjusted posttest means of the groups were not significant for simple reaction time, simple movement time, or discrimination reaction time. Significant relationships between pretest $\mathrm{VO}_{2} \max$ and discrimination reaction time, and between posttest $\mathrm{VO}_{2}$ max and discrimination movement time, were found, $\mathrm{p}<.05$. There were no significant relationships between simple reaction time or simple movement time and $\mathrm{VO}_{2} \mathrm{max}$, either pre- or posttest. There was also no significant relationship between pretest $\mathrm{VO}_{2} \max$ and pretest discrimination movement time or between posttest $\mathrm{VO}_{2} \max$ and posttest discrimination reaction time. Changes in $\mathrm{VO}_{2}$ max were not significantly 
correlated with changes in simple or discrimination reaction time or movement time.

\section{Conclusions}

The following conclusions can be drawn based on the results of this study:

1. Ten weeks of aerobic exercise are not sufficient to improve simple reaction time, simple movement time, or discrimination reaction time in healthy 34-46 year old women, despite improvements in fitness.

2. Discrimination movement time was significantly faster in healthy 34-46 year old women compared to a control group following participation in 10 weeks of aerobic exercise. This is attributed to a task time trade-off between reaction time and movement time.

3. Significant relationships between pretest $\mathrm{VO}_{2} \max$ and discrimination reaction time and between posttest $\mathrm{VO}_{2}$ max and discrimination movement time indicate that fitness is an important contributor to psychomotor speed as the complexity of the task increases, and that both central and peripheral components of response time are affected by fitness. Moreover, these results provide further support for a task time trade-off between reaction and movement time obtained from the same response time task.

4. Changes in fitness, as estimated from a one mile walk test, are not related to changes in simpie or discrimination reaction or movement time. 


\section{Recommendations}

Based upon the results of this study, a short duration exercise program is not sufficient to improve CNS efficiency in 34 to 46 year old women. However, longer duration research and cross-sectional studies with active subjects support lifelong physical activity as a means of preventing declines in response speed with age. Thus people of all ages should be encouraged to exercise regularly to maintain both physical and mental health, while continued research in this area attempts to more clearly define the relationship between exercise and psychomotor speed.

The following recommendations for future research on physical activity and its efíect on response time components are made based on the findings of this study:

1. Reaction time should be measured independent of a movement time task when the primary interest is the effect of exercise on CNS efficiency.

2. Fractionated response time measures should be further investigated with regard to the observed task time trade-off between reaction and movement time to determine if the trade-off is between the peripheral components of motor time and movement time or between premotor time and movement time.

3. To address the question of why a task time trade-off occurred only in the exercise group in the present study, additional research examining the effects of exercise training on fractionated response time measures is warranted.

4. To determine whether movement time as measured in a reaction/movement time task is specific to the musculature used in training, the 
effect of eridurance exercise on movement times of the upper and lower extremities should be simultaneously examined.

5. Long term training studies (in excess of three months) are needed to determine if response time components can be maintained and/or improved by longer duration increases in physical activity, and whether age, exercise intensity or initial $\mathrm{VO}_{2}$ max interact to effect when such changes occur.

6. In addition to $\mathrm{VO}_{2} \max$, other physiological and psychological variables, such as ventilatory responses, blood pressure, heart rate, anxiety and happiness levels, known to be impacted by exercise and aging should be measured across training studies.

7. Response time components and other variables of interest should be measured periodically throughout the training period to identify when physiologica! and psychological adaptations occur. 


\section{References}

Abourezk, T. (1990). The relationship arnong cognitive complexity, oxygen, and activity level in older women. Unpublished doctoral dissertation, Florida State University.

Abrahams, J. P., \& Birren, J. E. (1973). Reaction time as a function of age and behavioral predisposition to coronary heart disease. Journal of Gerontology, 28, 471-478.

American College of Sports Medicine (1991). Guidelines for exercise testing and prescription (4th ed.). Philadelphia: Lea \& Febiger.

American Heart Association (1972). Exercise testing and training of apparently healihhy individuals: A handbook for physicians (p. 15). Dallas: American Heart Association.

Aniansson, A., Grimby, G., Hedberg, M., \& Krotkiewski, M. (1981). Miuscle morphology, enzyme activity and muscle strength in elderly men and women. Clinical Physiology, 1, 73-86.

Barry, A. J., Daly, J. W., Pruett, E. D. R., Steinmetz, J. R., Page, H. F., Birkhead, N. C., \& Podahl, K. (1966a). The effects of physical conditioning on older individuals. I. Work capacity, circulatory-respiratory function, and work electrocardiogram. Journal of Gerontology 21, 182-191.

Barny, A. J., Steinmetz, J. R., Page, H. F., \& Rodainl, K. (1966b). The effects of physical conditioning on older individuals. II. Motor performance and cognitive function. Journal of Gerontology, 21, 192-199. 
Baylor, A. M. (1989). Plasticity and exercise effects on aging motor function. In M. H. Woollacott \& A. Shumway-Cook (Eds.), Development of Posture and Gait Across the Life Span (pp. 202-225). Columbia, SC: University of South Carolina Press.

Baylor, A. M., \& Spirduso, W. W. (1988). Systematic aerobic exercise and components of reaction time in older women. Journal of Gerontology, 43⑸, P121-P126.

Beise, D., \& Peaseley, V. (1932). The relation of reaction time, speed, and agility of big muscle groups to certain sports skills. Research Quarterly, 8, 133-142.

Birren, J. E., Woods, A. M., \& Williams, M. V. (1979). Speed of behavior as an indicator of age changes and the integrity of the nervous system. In $\mathrm{F}$. Hoffmeister \& C. Miller (Eds.), Brain function in old age (pp. 10-44). New York: Springer-Verlag.

Boarmar, A. M. (1978). The effect of folk dancing upon reaction time and movement time of senior citizens. Dissertation Abstracts international, 38, 5329A-5330A. (University Microfilms No. 77-32, 544)

Botwinick, J., \& Thompson, L. W. (1966). Components of reaction time in relation to age and sex. Journal of Genetic Psychology, 108, 175-183.

Brown, W. F. (1972). A method for estimating the number of motor units in thenar muscles and the change in motor unit count with ageing. Journal of Neurology, Neurosurgery, and Psychiatry 35, 845-852. 
Cerella, J., Poon, L. W., \& Williams, D. M. (1980). Age and the complexity hypothesis. In L. W. Poon (Ed.) Aging in the 1980s: Psychological issues (pp. 332-340). Washington, D. C.: American Psychological Association.

Chodzko-Zajko, W. J., \& Ringel, R. L. (1987). Physiological fitness measures and sensory and motor performance in aging. Experimental Gerontology 22, 317-328.

Clarkson, P. M. (1978). The effect of age and activity level on simple and choice fractionated response time. European Journal of Applied Physiology, 40 , 17-25.

Cowan, M. M., \& Gregory, L. W. (1985). Responses of pre- and postmenopausal females to aerobic conditioning. Medicine and Science in Sports and Exercise, $17(1), 138-143$.

Dusiman, R. E., Ruhling, R. O., Russell, E. M., Shearer, D. E., Bonekat, W., Shigeoka, J. W., Wood, J. S., \& Bradiord, D. C. (1984). Aerobic exercise training and improved neuropsychological function of older individuals. Neurobiology of Aging, $\underline{5}, 35-42$.

Dzewaltowski, D. A. (1985). The effect of aerobic exercise on information processing in older adults. Unpublished master's thesis, West Virginia University, Morgantown, West Virginia.

Eccles, J. C. (1973). Trophic influences in the mammalian central nervous system. In M. Rockstein (Ed.), Development and aging in the nervous system (pp. 89-103). New York: Academic Press. 
Eia, P., Jokela, J., \& Heikkinen, E. (1986). Reaction and movement times in men of different ages: A population study. Perceptual and Motor Skills, 63, 111-130.

Faulkner, J. A., Maxwell, L. C., \& Lieberman, D. A. (1972). Histochemical characteristics of muscle fibers from trained and detrained guinea pigs. American Journal of Physiology, 222(4), 836-840.

Feldman, M. L., \& Dowd, C. (1975). Loss of dendritic spines in aging cerebral cortex. Anatomy and Embryology, 148, 279-301.

Fletcher, L. M. (1985). The relation of maximal oxygen uptake and hyperoxia to reaction and movement times in older men and women. Unpublished master's thesis, Pennsylvania State University.

Flint, M. M., Drinkwater, B. L., \& Horvath, S. M. (1974). Effects of training on women's response to submaximal exercise. Medicine and Science in Sports, $\underline{6}, 89-94$.

Floeter, M. K., \& Greenough, W. T. (1979). Cerebellar plasticity: Modification of Purkinje cell structure by differential rearing in monkeys. Science, 206(12), 227-229.

Forth, C. D., \& Salmoni, A. W. (1987). Relationships among self-reported physical activity, aerobic fitness and reaction time. Canadian Journal of Sports Science, 13(1), 88-90.

Fox, E. L., Bowers, R. W., \& Foss, M. L. (1988). The physiological basis of physical education and athletics (4th Ed., pp. 324-330, p. 698). Dubuque, IA: William C. Brown Publishers. 
Gross, P. M., Marcus, M. L., \& Heistad, D. D. (1980). Regional distribution of cerebra! blood flow during exercise in dogs. Journal of Applied Physiology, 48(2), 213-217.

Hascelik, Z., Basgoze, O., Turker, K., Narman, S., \& Ozker, R. (1989). The effects of physical training on physical fitness tests and auditory and visual reaction times of volleyball players. Journal of Sports Medicine and Physicai Fitness, 29(3), 234-239.

Heyward, V. H. (1991). Advanced fitness assessment and exercise prescription (2nd ed., pp. 165-167). Champaign, iL: Human Kinetics Books.

Hicks, L. H., \& Birren. J. E. (1970). Aging, brain damage and psychomotor siowing. Psychological Bulletin, 74(6), 377-396.

Hodgkins, J. (1963). Reaction time and speed of movement in males and females of various ages. Research Quarterly, 344(3), 335-343.

Ingjer, F. (1978). Maximal aerobic power related to the capillary supply of the quadriceps femoris muscle in man. Acta Physiologica Scandinavica, 104. 238-240.

Jacobs, E. A., Winter, P. M., Alvis, H. J., \& Small, S. M. (1969). Hyperoxygenation effect on cognitive functioning in the aged. The New England Journal of Medicine, 281(14), 753-757.

Jette, M., Sidney, K., \& Campbell, J. (1988). Effects of a twelve-week walking programme on maximal and submaximal work output indices in sedentary middle-aged men and women. Journal of Sports Miedicine and Physical Fitness, 28(1), 59-66.

Kety, S. S. (1956). Human cerebral blood flow and oxygen consumption as related to aging. Journal of Chronic Diseases, $\underline{3}, 478-486$. 
Kline, G. M., Porcari, J. P., Hintermeister, R., Freedson, P. S., Ward, A., McCarron, R. F., Ross, J., \& Rippe, J. M. (1987). Estimation of VO2max from a one-mile track walk, gender, age, and body weight. Medicine and Science in Sports and Exercise, 19(3), 253-259.

Knapp, B. N. (1961). Simple reaction times of selected top-class sportsmen and research students. Research Quarterly, 32(3), 409-411.

Kroll, W., \& Clarkson, P. M. (1978). Age, isometric knee extension strength, and fractionated resisted response time. Experimental Aging Research, 4(5), 389-409.

Landfield, P. W., Lindsey, J. D., \& Lynch, G. (1978). Apparent acceleration of brain aging pathology by prolonged administration of glucocorticuids. Society for Neuroscience Abstracts, 4, 118(Abstract No. 350).

Larsson, L. (1982). Aging in mammalian skeletal muscle. In J. A. Mortimer, F. J. Pirozzolo, \& G. J. Maletta (Eds.), Advances in neurogerontology: Vol. 3. The aging motor system (pp. 60-97). New York: Praeger.

Lexell, J., Henriksson-Larsen, K., Winblad, B., \& Sjostrom, M. (1983).

Distribution of different fiber types in human skeletal muscles: Effects of aging studied in whole muscle cross sections. Muscle \& Nerve, $\underline{6}, 588$ 595.

McArdle, W. D., Katch, F. I., \& Katch, V. L. (1991). Exercise physiology: Energy, nutrition, and physical performance (pp. 359-363, 616-6i8).

Philadelphia: Lea and Febiger.

McFarland, R. A. (1963). Experimental evidence of the relationship between ageing and oxygen want: in search of a theory of ageing. Ergonomics, 6, 339-366. 
Melamed, E., Lavy, S., Bentin, S., Cooper, G., \& Rinot, Y. (1980). Reduction in regional cerebral blood flow during normal aging. Stroke 11(1), 31-34.

Normand, R., Kerr, R., \& Metivier, G. (1987). Exercise, aging and fine motor performance: An assessment. Journal of Sports Medicine and Physical Fitness, 27, 488-496.

Olsen, E. A. (1956). Relationship between psychological capacities and success in college athletics. Research Quarterly, 27, 79-89.

Panton, L. B., Graves, J. E., Pollock, M. L., Hagberg, J. M., \& Chen, W. (1990). Effect of aerobic and resistance training on fractionated reaction time and speed of movement. Journal of Gerontology, 45(1), M26-M31.

Pierson, W. R., \& Montoye, H. J. (1958). Movement time, reaction time, and age. Journal of Gerontology, 13, 418-421.

Powell, R. R. (1983). Reaction time changes following aerobic conditioning. Journal of Human Movement Studies, $\underline{9}$, 145-150.

Pysh, J. J., \& Weiss, G. M. (1979). Exercise during development induces an increase in Purkinje cell dendritic tree size. Science 206(12), 230-232.

Rikli, R., \& Busch, S. (1986). Motor performance of women as a function of age and physical activity level. Journal of Gerontology 41(5), 645-649.

Rikli, R. E., \& Edwards, D. J. (1991). Effects of a three-year exercise program on motor function and cognitive processing speed in older women. Research Quarterly for Exercise and Sport 62(1), 61-67.

Roberts, B. L. (1990). Effects of walking on reaction and movement times among elders. Perceptual and Motor Skills, 71, 131-140.

Rockport Walking Institute (1986). Rockport fitness walking test. Marlboro, MA: Rockport Walking Institute. 
Rudisill, M. E., \& Toole, T. (1992). The effects of a physical activity program on reaction time and movement time for the older adult. Journal of Human Movement Studies, 22 , 205-212.

Schmidt, R. A. (1988). Motor control and learning: A behavioral emphasis. Champaign, lil: Human Kinetics.

Schroeder, R. (1990). Assessing fitness. Your quide to a healthy lifestyle (p. 82). Dubuque, IA: Kendall/Hunt.

Sherwood, D. E., \& Selder, D. J. (1979). Cardiorespiratory heaith, reaction time and aging. Medicine and Science in Sports, 11(2), 186-189.

Smith, B. H., \& Sethi, P. K. (1975). Aging and the nervous system. Geriatrics, 30, 109-115.

Spirduso, W. W. (1982). Physical fitness in relation to motor aging. In J. A. Mortimer, F. J. Pirozzolo, \& G. J. Maletta (Eds.), Advances in neurogerontology: Vol. 3. The aging motor system (pp. 120-151). New York: Praeger.

Spirduso, W. W. (1980). Physical fitness, aging, and psychomotor speed: A review. Journal of Gerontology, 35(6), 850-865.

Spirduso, W. W. (1975). Reaction and movementit time as a iunction of age and physical activity level. Journal of Gerontology 30(4), 435-440.

Spirduso, W. W., \& Clifford, P. (1978). Replication of age and physical activity effects on reaction and movement time. Journal of Gerontology, 33(1). 26-30.

Stacey, C., Kozma, A., \& Stones, M. J. (1985). Simple cognitive and behavioural changes resulting from improved physical fitness in persons over 50 years of age. Canadian Journal on Aging, 4(2), 67-74. 
Tolson, H. (1980). An adustment to statistical significance: $w^{2}$. Research Quarterly for Exercise and Sport, 51(3), 580-584.

Tomonaga, M. (1977). Histochemical and ultrastructural changes in senile human skeletal muscle. Journal of the American Geriatrics Society, 25 , 125-131.

Toole, T., \& Abourezk, T. (1989). Aerobic function, information processing, and aging. In A. C. Ostrow (Ed.), Aging and motor behavior (pp. 37-65). Indianapolis, IN: Benchmark Press.

Tweit, A. H., Gollnick, P. D., \& Hearn, G. R. (1963). Effect of training program on total body reaction time of individuals of low fitness. Research Quarterly, 34(4), 508-513.

Vanfraechem, J., \& Vanfraechem, R. (1977). Studies of the effect of a short training period on aged subjects. Journal of Sports Medicine and Physical Fitness, 17 , 373-380.

Weiss, A. D. (1965). The locus of reaction time change with set, motivation and age. Journal of Gerontology, 20, 60-64.

West Virginia University (1988). Physical fitness and the aging driver. (Report No. CG 022 007).

Whitehurst, M. (1991). Reaction time unchanged in older women following aerobic training. Perceptual and Motor Skills, 72, 251-256.

Youngen, L. (1959). A comparison of reaction and movement times of women athletes and nonathletes. Research Quarterly 30(3), 349-355.

Zwiren, L. D., Freedson, P. S., Ward, A., Wilke, S., \& Rippe, J. M. (1991). Estimation of VO2max: A comparative analysis of five exercise tests. Research Quarterly for Exercise and Sport 62(1), 73-78. 


\section{Appendix A}

\section{HEALTH HISTORY QUESTIONNAIRE}

Please complete the following health history to the best of your ability. Contact your health care provider as necessary to ensure this record is as accurate and complete as possible. This information will be used in defermining your eligibility to participate in this research study, and in prescribing an exercise program for you. All information will be kept confidential.

Name _ Age _ _ Birthdate

Mailing Address:

Phone\#. Home: Work: $(1$ Height: Weight:

Personal Physician (Local):

Address:

Phone\#.

Person to Contact in Case of an Emergency:

Address:

Relationship to you:

Phone \#: Home:

Work: $(1)$

\section{MEDICAL (CHECK IF YES)}

1. In the past have you ever had:

( ) Heart Attack/Stroke
When?
( $)$ Rheumatic Fever
Heart Murmur
Heart Surgery
Heart Rhythm Abnormalities
High Blood Pressure ( $160 / 90 \mathrm{mmHg})$
$(\quad)$ Disease of Arteries
Varicose Veins
$(\quad)$ Lung Disease
Injuries to back, knees or ankles
Epilepsy or convulsions
Diabetes or abnormal blood sugar test
Hernias

( ) Allergic Reactions
Explain:
Tuberculosis
Bronchitis
Asthma
Arthritis of legs or arms
Abnormal chest X-ray
Dizziness or fainting spells
Scariet Fever
Anemia
Urinary tract infections, kidney
stones, prostate problems
$(\quad)$ Elevated cholesterol $(>240)$
None of the above

2. Have any of your blood relatives had: (include parents, sisters, brothers, aunts, uncles, grandparents)
Diabetes
) Congenital heart disease
) Asthma or hay fever
) Obesity


3. Have you recently (in the past 6 months) had:

() $\begin{aligned} & \text { Chest pain or pressure } \\ & \text { Shortness of breath } \\ & \text { Heart palpitations } \\ & \text { (sudden fast heart rate) }\end{aligned}$
$\left(\begin{array}{l}\text { Light headedness or dizziness } \\ \text { Cough on exertion }\end{array}\right.$
() Coughing up blood
Back pain

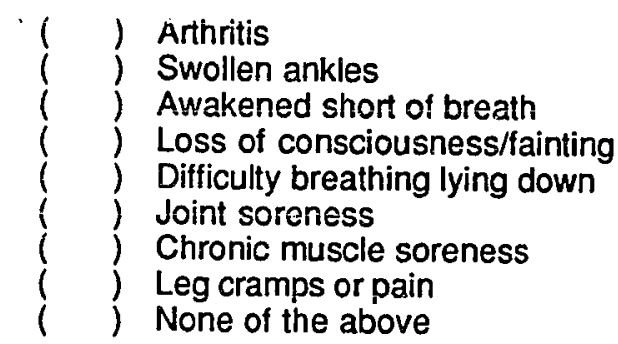

4. List any prescribed medication you are now taking.

5. List any medication or diet supplements you now take.

6. Date of last complete:

Physical Exam: __ Month
Chest X-Ray:
Electrocardiogram:

7. Have you ever smoked cigarettes, cigars or a pipe?

If yes, do you presently smoke?

If no, when did you quit? Month

Results were normal Abnormal

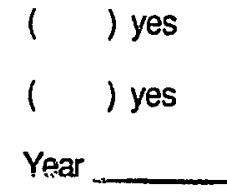

8. Have you ever had any major chronic skeletal or muscular injuries?

If yes, explain: 
9. List hospitalization, including dates and reasons for hospitalizations:

10. List any allergies (including drug allergies):

11. Please explain any other significant medical problem(s) that you consider important for us to know.

12. Have you ever been advised by a physician not to exercise because of a medical problem? If yes, please explain

13. How would you describe your health? ( )poor ( )fair i )average

( Igood ( )excellerit

14. Are you or have you recently been pregnant?_____ If so, when did you deliver?

\section{NUTRITION AND EXERCISE}

1. What is your weight now? One year ago? At age 21?

2. Are you on a special diet? Why?

3. Cups per day: Coffee Wine Beer Other Alcohol

4. Body Build: Slender Medium Heaw Obese

5. Were you a high school or college athlete? (Specify)

6. Do you have discomfort, shortness of breath or pain with moderate exercise? (Specify) 
7. How often in the past six months did you engage in the following activities at a MODERATE INTENSITY for 30 CONTINUOUS MINUTES OR MORE?

ACTIVIT

Running or Jogging

Hiking or Outdoor Walking

Bicycling

Swimming

Tennis

Dancing

Other (specify)

\section{1-2 TIMES 3-6 TIMES}

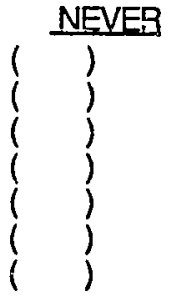

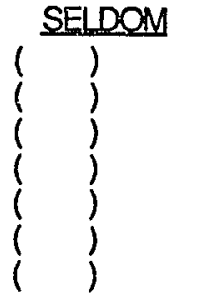

$(j)$
$(j)$
$(j)$

8. How physically fit do you feel at the present time?

i Unfit ()Below Average ( )Average () Above Average ( ) Very Fit

9. Please specify with a check days/times you would be available to come to San Jose State University for testing and exercise training:

Monday Tuesday Wednesday Thursdav Friday Saturday Sunday

$6 a m$

Zam

8 am

2am

$10 \mathrm{am}$

$11 \mathrm{am}$

$12 \mathrm{pm}$

$1 \mathrm{pm}$

$2 \mathrm{pm}$

$3 . \mathrm{pm}$

$4 \mathrm{pm}$

$5 \mathrm{pm}$

$6 \mathrm{pm}$

Iom

10. Do you drive an automobile?

Yes No

I certify that, to the best of my knowledge, the aforegoing answers are accurate and true. 
Appendix B

\section{INFORMED CONSENT}

\section{AGREEMENT TO PARTICIPATE IN RESEARCH}

Responsible investigators: Lynne Flachman, \& V. Gregory Payne, P. E. D.

Title of Protocol: The Effect of Aeroblc Training on Simple and Discrimination Reaction Time and Movement Speed.

\section{Pre-testing procedures:}

You have been asked to take part in a research study investigating the effects of aerobic training on simple and discrimination reaction and movement time. You will be asked to complete a series of timing tests and a one mile walk iest. You will be asked to meet in the Exercise Physiology Laboratory in the Spartan Complex building, room SPX 208 at San Jose University at your scheduled testing time. Prior to testing we ask that you:

(1) Do not eat solid food, smoke cigarettes, or drink caffeinated beverages two hours prior to your testing time.

(2) Have a good nights sleep prior to your arrival.

(3) Arrive on time to keep testing times on schedule.

(4) Wear comfortable clothing: shorts, socks, running or athletic shoes.

(5) Avoid unusual or rigorous exercise 24 hours prior to testing.

(6) Call (408) 883-0281 or (408) 924-3017 to cancel testing if you suffer from acute injury or illness that may impair your physical ability to perform on your testing day.

\section{Testing Procedures:}

You will be participating in a three part testing series lasting approximately two hours.

Parta

To assess body composition and size, your height, body weight, and skinfold thicknesses (skin caliper method) will be measured. Resting blood pressure and resting heart rate will also be obtained.

PartB

To assess timing behavior, you wi!l be asked to perform 180 reaction/movement time trials. In the reaction/movement time trials you will be asked to rest your right foot on a switch pad. Your task wili be to move your foot as quickly as possible to another switch pad following the appropriate light stimulus. The movement will be similar to moving from the accelerator to the brake in an automobile.

Pantc

In the third portion of testing procedures you will be fitted with a heart rate monitor and asked to walk for one mile as fast as you can. Either you or we may stop the test at any time in the case of extreme fatigue or discomfort. 
III. Training Procedures:

If you are participating in the training portion of this study, you will be asked to meet three days each week at a specified time and place, for a duration of approximately one hour. Following approximately a five minute warm-up, you will walk and/or jog from 20 to 50 minutes, as specified by the investigator, followed by a five minute cool down period. Your training intensity will be determined using your age-predicted maximum heart rate and subjective ratings of perceived exertion. You will also be asked to complete one additional training session each week on your owiti ime. The training period will last for ten weeks.

\section{Risks and discemforts associated with testing and iraining:}

\section{PartA}

Body composition and size measurements pose no known risk or discomfort.

\section{Part B}

Reaction time and movement time testing pose no known risk or discomfort.

\section{Part $C$ and Training Procedures}

You will experience normal discomforts associated with exercise including sweating, increased heart and breathing rates, and raised body temperature. You may also experience muscle soreness as an outcome of the testing or exercise program. There exists the possibility of cerlain changes occurring during exercise. They include abnormal biood pressure, fainting, disorder of heari beat, and in rare instances, heart attack, stroke, or death. CPR certified personnel will be present for all exercise testing and training sessions to ensure maximal safety. Every effort will be made to minimize possible risks through preliminary examinations and observations during testing, and a gradual build up of training intensity and duration. You will be made aware of any signs or symptoms contraindicative to testing prior to your walking test.

\section{v. Benefits to testing:}

\section{All Subjects:}

The reaction/movement timing tests are fun and results will be provided to you during the testing. Results of the walkirig test, which assesses your cardiorespiratory fitness, will be analyzed and reviewed with you. In addition, you will be participating in a rescarch study whose results may improve our understanding of the role of exercise in promoting good health.

\section{Training Subjects:}

You will participate in a free, ten week, structured exercise program designed to improve your cardiorespiratory fitness.

\section{Control Subjects:}

Following the second testing session, you will meet with the researcher individually to review timing and fitness test results. Information and assistance in designing an appropriate exercise program to meet your needs will be provided. 
VI. Inquiries, Withdrawal of Consent, and Confidentiality:

You may ask any questions you have pertaining to the testing or training procedures. Contact Lynne Flachman at (408) 883-0281 or (408) 924-3017 or Dr. Gregory Payne at (408) 9243028 for explanations if you have any questions or doubts.

You may withdraw your consent and discontinue participation at any time (including during the testing) without prejudice. You are free to decline to answer any specific item or question on the medical history questionnaire.

The data generated may be used for medical and/or scientific purposes, including publication and presentation at professional meetings but participants' identities will remain confidential.

Questions or complaints about the research, subjects' rights, or research-related injury may be presented to Dr. James Bryant at (408) 924-3010 or Serena Stanford, Ph.D., Associate Academic Vice President for Graduate Studies and Research at (408) 924-2480.

\section{VIll. Consent:}

I have read and understand the testing procedures described above and give my consent to participate. I understand that I am free to withdraw from the study at any time without penialty and without prejudice to my relations with San Jose State University.

\begin{tabular}{ll}
$\overline{\text { Subject's Signature }}$ & $\overline{\text { Date }}$ \\
\hline Investigator's Signature & \\
Date.
\end{tabular}

Subject i.o. \# 
Appendix C

\section{RESPONSE TIME DATA SHEET}

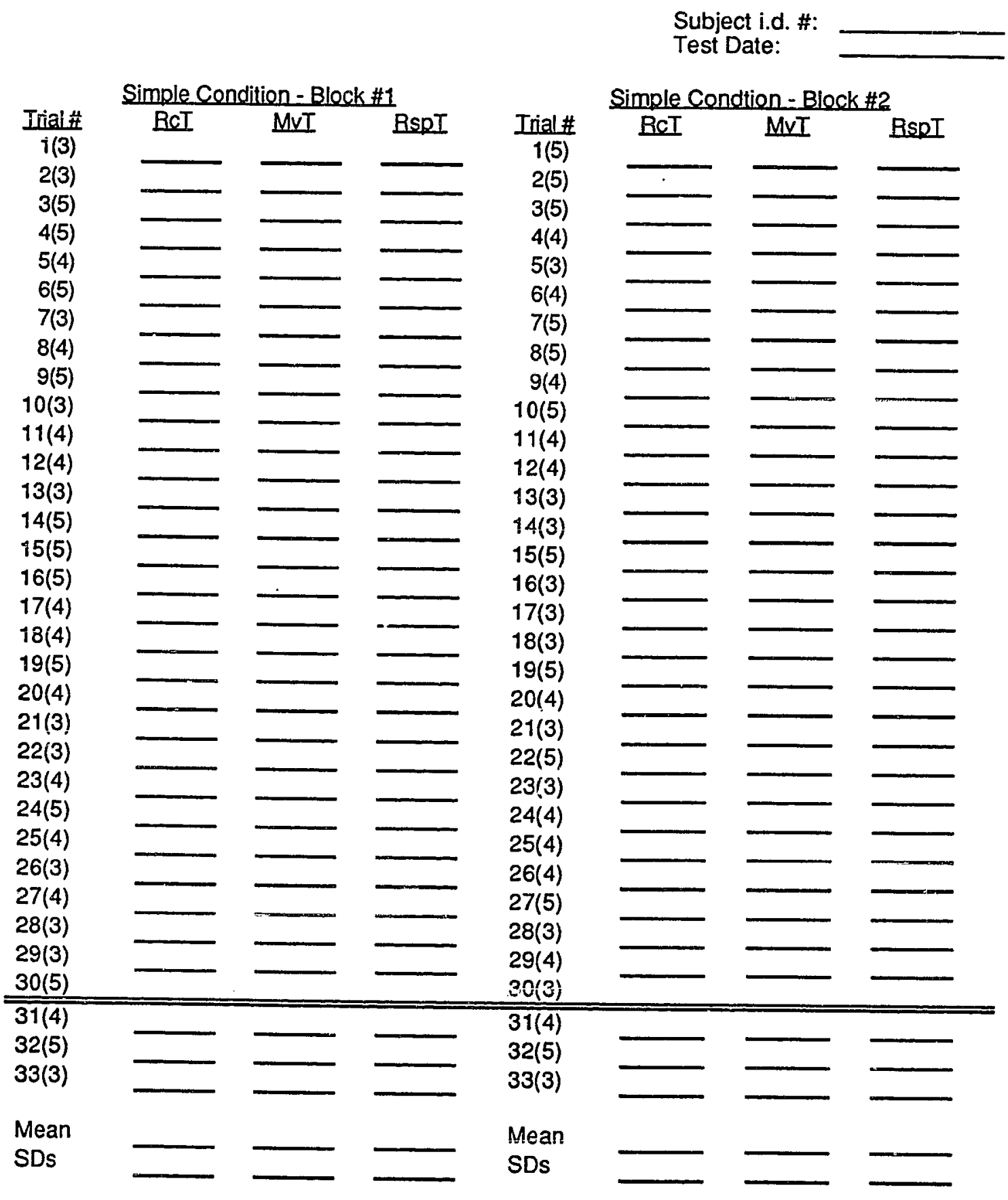


RESPONSE TIME DATA SHEET (p. 2)

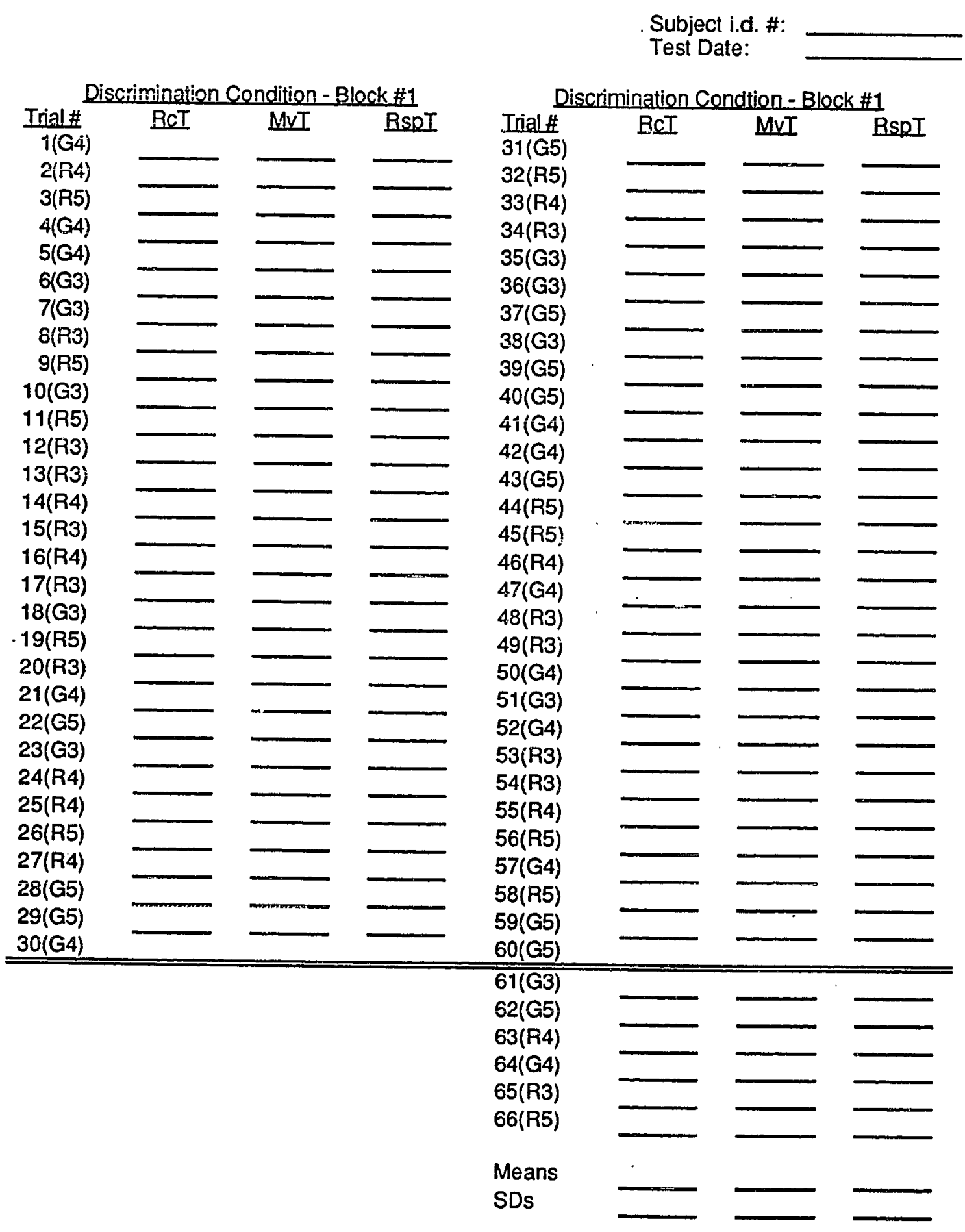


RESPONSE TIME DATA SHEET (p. 3)

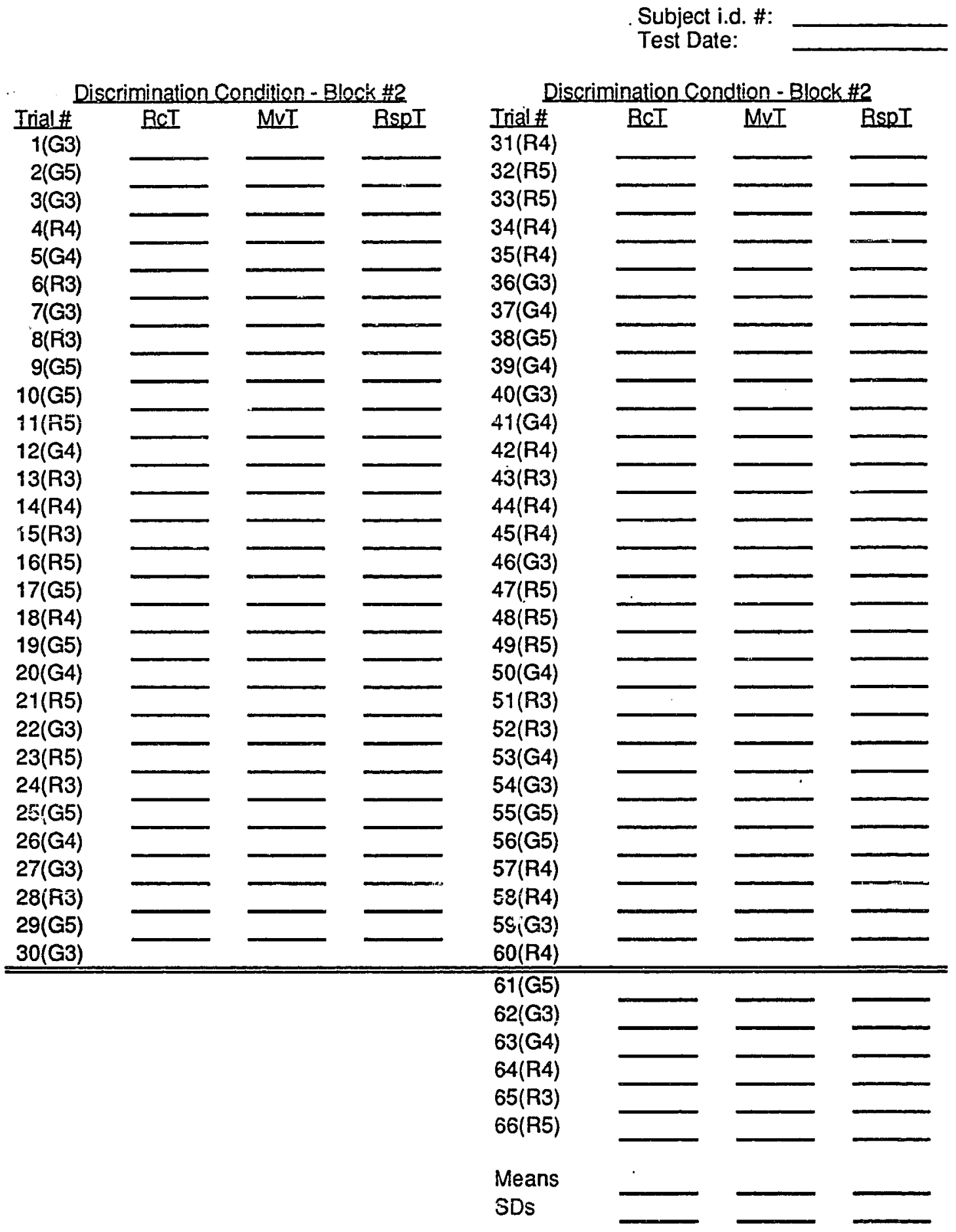


Appendix D

\title{
SUMMARY DATA SHEET
}

\author{
EXERCISE/CONTROL \\ SRT/CRT \\ PRETEST/POSTEST
}

Subject i.d. \#:

Test Date:

Test Time:

\section{Body Composition and Size}

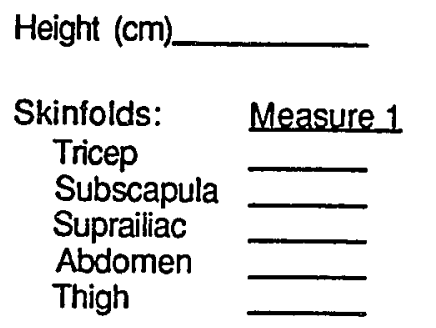

Weight $(\mathrm{kg})$

BMl $(\mathrm{kg} / \mathrm{m} 2)$

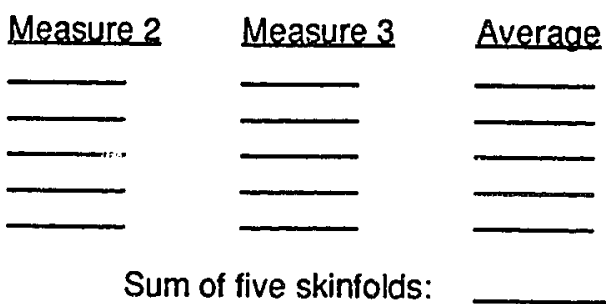

Beaction and Movement Time

Simple Condition, Elock 1:

Simple Condition, Block 2:

Combined, Simple:

Discrimination Condition, Block 1:

Discrimination Condition, Block 2:

Combined, Discrimination:

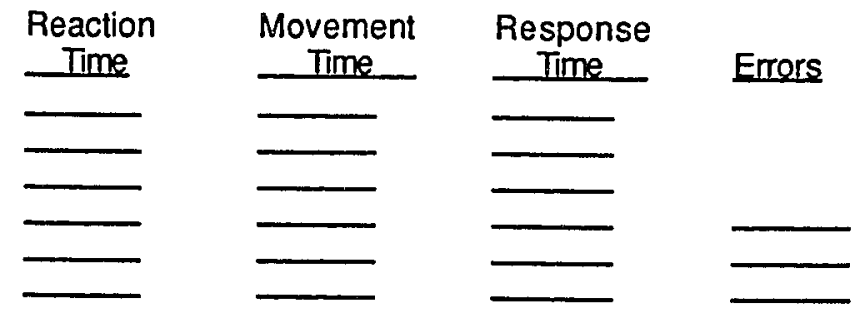

Voemax Estimation

Total Walk Time (Minutes)

Age (Years)

Average Heart Rate (BPM)

Weight (lbs)

Split Times:

Lap 1 Lap2 Lap3 Lap 4

Equation: VO2max $(\mathrm{m} / \mathrm{kg} / \mathrm{min})=132.853-0.0769 \times$ Weight $\left(\_\right.$los $)-0.3877^{*}$ Age - 3.2649*Walk Time ( min)- $0.1565^{*}$ Average Heart Rate ( BPMi) ys) Estimated VO2max: $\mathrm{ml} / \mathrm{kg} / \mathrm{min}$ 
Appendix E

\section{RATING OF PERCEIVED EXERTION OR "RPE" CHART}

During your workout I want you to try to estimate how hard you feel the work is; that is, I want you to rate the degree of perceived exertion you fee! (RPE). By perceived exertion I mean the total amount of exertion and physical fatigue, combining all sensations and feelings of physical stress, effort, and fatigue. Don't concern yourself with any one factor such as leg pain, shortness of breath, or the work intensity, but try to concentrate on your total, inner feeling of exertion. Try to estimate as honestly and objectively as possible. Don't underestimate the degree of exertion you feel because you think the work "should" feel easy, but don't overestimate it either.

You may use any number on the scale (whether or not a description is associated with it). A rating of $1 \overline{9}$ (very, very hard) should be associated with the heaviest or most stressful exercise ever performed. Keep in mind that there are no right or wrong answers. Use any number you think is appropriate. Do not be swayed by what others report; different individuals will have different feelings for the same amount of work.

Borg Scale for Rating of Perceived Exertion

$\begin{array}{cl}\text { Perceived Exertion Rating } & \text { Description } \\ 6 & \text { very, very light } \\ 7 & \\ 8 & \text { very light } \\ 9 & \\ 10 & \text { fairly light } \\ 11 & \\ 12 & \text { somewhat hard } \\ 13 & \text { hard } \\ 14 & \\ 15 & \text { very hard } \\ 16 & \\ 17 & \text { very, very hard } \\ 18 & \\ 19 & \\ 20 & \end{array}$




\section{STANDARDIZED INSTRUCTIONS}

\section{SIMPLE RESPONSE TIME INSTRUCTIONS}

1. Sit with your back against the chair.

2. When I say "Ready," depress the end of the right foot pad with your right foot.

3. A white warning light will come on here (point to light) which lets you know a new "trial" is about to start. Please keep your foot depressed after the white light appears.

4. Shortly after the white light (between 3 to 5 seconds), this light here (point to light) will flash red.

5. When it does, move ycur foot as quickly as possible to depress the left foot pad. As soon as you have pushed down the left pad, you can release it.

6. You will complete 30 trials, rest for 3 minutes, then ccmplete 30 more.

\section{DISCRIMINATION RESPONSE TIME INSTRUCTIONS}

1. Sit with your back against the chair.

2. When I say "Ready," depress the end of the right foot pad with your right foot.

3. A white warning light will come on here (point to light) which lets you know a new "trial" is about to start. Please keep your foot depressed after the white light appears.

4. Shortly after the white light (between 3 to 5 seconds), this light here (point to light) will flash red or green.

5. If it flashes red, move your foot as quickly as possible to depross the left foct pad. As soon as you have pushed down the left pad, you can release it.

6. If it flashes green, maintain depression of your foot on the pad until I instruct you to take it off and depress the left pad.

7. You may get several red or several green trials in a row. Please be sure you move only when there is a red light; movements when the light is green are counted as errors.

8. You will complete 60 trials, rest for 3 minutes and complete 60 more. 